\title{
Stochastic Programming of Sustainable Waste Cooking Oil for Biodiesel Supply Chain under Uncertainty
}

\author{
Nana Geng $\mathbb{D}^{1},{ }^{1}$ Qihong Fu, ${ }^{1}$ and Yixiang Sun $\mathbb{D}^{2}$ \\ ${ }^{1}$ Nanjing University of Posts and Telecommunications, Nanjing 210023, China \\ ${ }^{2}$ Nanjing University of Aeronautics and Astronautics, Nanjing 211106, China \\ Correspondence should be addressed to Yixiang Sun; sunyixiang@nuaa.edu.cn
}

Received 13 May 2021; Revised 4 July 2021; Accepted 7 July 2021; Published 20 July 2021

Academic Editor: xinyuan chen

Copyright (c) 2021 Nana Geng et al. This is an open access article distributed under the Creative Commons Attribution License, which permits unrestricted use, distribution, and reproduction in any medium, provided the original work is properly cited.

As an important emission reduction source for the transportation industry, biofuel has received strong support from the Chinese government. However, the development of the biofuel industry is still struggling. The high degree of uncertainty makes the development of the industry face huge challenges. Kitchen waste, as a biodiesel raw material with a large yield, has good development prospects. Reuse of kitchen waste can solve public health and safety problems. This paper proposes a two-stage stochastic programming model under supply disturbance to optimize the supply chain from the perspective of contract. Then current three main flow directions of kitchen waste are analysed and the reasonable price for biodiesel operators to purchase is determined. By signing contracts with the biodiesel operators, restaurant is guaranteed and encouraged to provide a certain percentage of kitchen waste to meet the demand for biodiesel production. Using actual case in the Yangtze River Delta region, the performance of the stochastic programming model under disturbance was compared. Through the sensitivity analysis of different parameters, this paper determines the influence of its supply chain network design and expected total system cost. Through the optimization of the waste cooking oil (WCO) for biodiesel supply chain, this paper can effectively improve the efficiency of the supply chain, reduce system costs, increase the profits of biofuel operators, and promote the sustainable development of the biofuel industry.

\section{Introduction}

In China, with the expansion of the bioenergy development planning in recent years, the amount of biodiesel needed in transport fuels is projected to increase. Moreover, the current biodiesel blend ratio of $5 \%$ in China is likely to increase to $15 \%$ or more in the near future, which will also create more biodiesel demand. To meet the growing demand of the biodiesel industry, society must provide more sustainable material to produce biodiesel. The Chinese government highly supports the development of the biodiesel industry with kitchen waste as the raw material. The development policy of the biodiesel industry (2015) clearly states that kitchen waste should become the main raw material of biodiesel, and its supply chain needs effective design to improve the overall operational efficiency. However, some studies have shown that few restaurants provide kitchen waste to biodiesel operators due to uncertainty of the implementation of kitchen waste production in most restaurants and the lack of understanding. Therefore, this paper will focus on putting forward strategies to increase the supply of kitchen waste in restaurants and reduce the cost of the WCO-biodiesel supply chain.

The paper firstly defines and describes the supply chain problems. Previous studies have shown that providing a financial benefit to restaurants is a viable way to encourage restaurants to provide kitchen waste $[1,2]$. Through signing a contract, ensure that restaurants sell a certain percentage of kitchen waste at a certain purchase price, which can effectively solve the problem of the uncertainty in the supply of raw materials for biodiesel [3]. Based on the above two models, the paper reconstructs the stochastic programming model under the supply disturbance. In this paper, biodiesel operators provide restaurants with the price of unit kitchen 
waste by signing contracts to achieve a stable supply source, and the price is determined by the restaurant's allocation decision model. The supply uncertainty of kitchen waste is an important factor in the design of supply chain network. Therefore, in the process of contract pricing and supply chain model construction, this paper also considers the uncertainty of the total supply of kitchen waste into the supply chain stochastic model construction, so as to enhance the antidisturbance of supply chain network. Based on the above two models, the paper reconstructed stochastic programming model of the supply chain. At last, we choose a case study and do the sensitivity analysis from transportation cost, pretreatment rate, kitchen waste residual value, and penalty fee. The research on the supply chain network in the biodiesel collection stage can facilitate the transportation of kitchen waste from restaurants to biodiesel refineries for biodiesel production. The structure of this paper is as follows. Section 1 analyses the research background and purpose of this paper. Section 2 reviews the relevant literature. In Section 3, the network optimization of the restaurant kitchen waste supply chain is described. In Section 4, the basic stochastic programming model, allocation decision model, and reconstructed stochastic programming model of the restaurant kitchen waste supply chain under supply disturbance are presented. Section 5 discusses the acquisition of data and discussion of results for the case study. Finally, in Section 6, the research results of this paper are summarized.

\section{Literature Review}

2.1. Biodiesel Supply Chain Uncertainty. In the supply chain, the supply is uncertain due to the capacity limitation of internal enterprises (endogenous factors) and the demand change of external market (exogenous factors). Uncertainty comes from all stages and activities in the biodiesel supply chain, and its type and degree are all different [4]. At present, a large number of literature studies reported that the problems in production, procurement, inventory management, coordination, and other aspects of the biofuel supply chain are caused by supply uncertainty. Zahraee et al. [5] considered the cost-effectiveness problem of the biofuel supply chain under the uncertainty of supply and built a deterministic planning and scheduling model aiming at minimizing the cost. Geng et al. [3] considered the problem of two-level supply chain composed of farmers and producers in the environment of uncertain supply and proposed a cooperation mechanism to improve the profit of each member in the supply chain, but it was limited to the case that market supply and demand fluctuated less. Giarola et al. [6] considered the uncertainty of biomass supply and carbon emission quota trading plan, aimed at maximizing the net present value of supply chain and minimizing carbon emissions, and established a multiperiod and multilevel mixed-integer linear programming model, so as to solve the problems of raw material allocation, production technology selection, and plant location of upstream supply chain of bioethanol. Osmani and Zhang [7] established a two-stage stochastic programming model to maximize profits and minimize carbon emissions and carried out a case study on biomass supply, biofuel demand, and price uncertainty in four Midwest states of the United States using wood fiber as raw material for biofuel supply chain. Biomass supply uncertainty is one of the most important uncertainty factors in the procurement process. As for agricultural waste, on the one hand, biomass depends on planting and harvesting operations and requires a relatively fixed growth cycle, so the supply of biomass presents obvious seasonal characteristics [8]. On the other hand, under the joint action of farmers' planting willingness, weather conditions, soil conditions, and other factors, biomass yield in different planting or harvesting periods and locations also presents certain differences [8, 9]. For waste cooking oil and other municipal wastes, on the one hand, biomass production depends on the dining consumption habits of urban residents and economic development, and so on, and there is a spatial-temporal difference. On the other hand, the actual amount of biomass collected by refining plants is also subject to competition from the illegal production industry chain of "gutter oil," which further aggravates the uncertainty of the amount of biomass. Nguyen and Chen [10] proposed a mathematical model to tackle the supplier selection and operation planning problem in biomass supply chains to help decision-makers facing uncertainty of biomass feedstock supply. Hu and Feng [11] model a supply chain of service requirement and supply and demand uncertainty with revenue sharing contract and derive the buyer's optimal ordering policy and the supplier's optimal supply policy. Lin et al. [12] analysed equilibrium solutions for the coopetitive supply chain across different channel structures under supply uncertainty.

\subsection{Mathematical Modelling Methods for Uncertain Problems.} In recent years, stochastic programming methods are mostly used to deal with supply uncertainty in the supply chain [13]. Stochastic programming is one of the emerging methods to deal with uncertain problems. The stochastic programming method was developed by Danzig and Beare, aiming to model random variables by using a set of discrete scenarios with known probabilities [14-17]. The demand assumption in stochastic planning is a random variable that obeys a uniform distribution, a normal distribution, or a Poisson distribution. Then, an optimal solution is found through stochastic programming to minimize (or maximize) the expected value of the objective function in the supply chain [18]. Due to the characteristics of supply chain design, twostage stochastic planning has been widely used in problems related to supply chain management [19]. In the first stage, the strategic or long-term decision of supplier selection (such as the number and combination of suppliers) should be made before the realization of random variables. When the random variables are realized, tactical and operational decisions such as order allocation, inventory, production, and transportation will be made in the second stage. When the model is constructed, the uncertainty problem is usually transformed into a deterministic mathematical 
programming method, which helps to minimize the impact of uncertainty factors. Dantzig et al. [20] proposed this concept and pointed out that stochastic programming can be divided into two types: two-stage stochastic programming model and multistage stochastic programming model. At present, two-stage stochastic programming is more common. Gupta and Maranas [21] pointed out that the twoorder stochastic programming in uncertain supply chain design can be divided into two models, namely, Wait and See model and Here and Now model. An et al. [22] studied the reliable $P$-median location problem using a two-stage robust model. Ghodratnama et al. [23] conducted robust and fuzzy target planning for the new multitarget hub location allocation problem. Stochastic programming has been gradually applied to various supply chain optimization and management problems.

2.3. Sustainability of Biodiesel Supply Chain. Sustainable supply chain design and optimization have become an emerging method, which tries to take environmental, economical, and social decisions into full consideration [24]. Geng and Sun [25] summarized the literature related to biodiesel supply chain optimization research. Economic sustainability means the most important objective of the biodiesel supply chain is to produce biodiesel in an economically viable manner [26]. Liu et al. [27] studied a mixedinteger linear programming model for optimizing economic, energy, and environmental objectives in a biofuel supply chain network design problem. The energy objective is measured by the fossil energy input per megajoule of biofuel production. Early work tends to focus on some environmental aspects of the engineering process, such as waste management and net heat consumption [28]. Giarola et al. [29] studied a biofuel supply chain network design model with the aim of cost and $\mathrm{CO}_{2}$-eqv. minimization. Social sustainability reflects as the development of the bioenergy industry is likely to create new employment opportunities and bring greater economic vitality in rural areas [30-33].

In general, the optimization of biodiesel supply chain is extremely important in the development system of the bioenergy industry. Scholars have done extensive research on theories and methods of biodiesel supply chain optimization, especially in the areas of biodiesel supply chain facility location. However, the theory of supply chain optimization using kitchen waste as raw material in view of China's national conditions is relatively insufficient. There are few papers on both the tactical design of sustainable supply chains and the optimization of biodiesel modelling under uncertain conditions. This paper introduces the strategy of price contract between restaurants and biofuel operators to guarantee restaurants to supply appropriate kitchen waste to biodiesel refineries. Through the construction of a two-stage stochastic programming model, the disturbance of kitchen waste supply was integrated into the design of biodiesel supply chain network. The negotiated purchase price of kitchen waste and the structure of biodiesel supply chain network were determined to ensure the normal operation of biodiesel refineries under disturbance.

\section{Problem Description}

WCO for biodiesel supply chain is a three-level supply chain including kitchen waste supply point, pretreatment facility, and the demand point (biodiesel refinery). The first level of kitchen waste supply point is the restaurants. The second level is the kitchen waste pretreatment facility, which is used for pretreating kitchen waste. It is built by the biodiesel operator according to the economic cost and environmental impact. The biodiesel operators can sell the excess kitchen waste at the pretreatment facility and buy the kitchen waste when the kitchen waste shortage occurs according to the demand of biodiesel and the supply of kitchen waste. The third level is biodiesel refinery, where all waste cooking oil processed by the pretreatment facility is transported to the refinery for biodiesel production. The kitchen waste is provided by the restaurants and transported by truck to the kitchen waste pretreatment facility, where the treated kitchen waste is transported to the biodiesel refinery, as shown in Figure 1.

Biodiesel production from kitchen waste faces more uncertainties in the future such as feedstock supply, biodiesel demand, and changing regulations and policies. According to statistics in the past 10 years, the total kitchen waste has increased by $1 \%-8 \%$ in different proportions [34]. The government has introduced a series of measures to reduce the amount of kitchen waste. Kitchen waste will continue to have obvious uncertainty in the future. The purpose of this paper is to establish a stochastic programming model considering the contract establishment and provide reliable solutions for designing the whole kitchen waste supply chain under the potential supply disturbances in the future. The specific problems to be solved by the stochastic programming model include the determination of the purchase price of the kitchen waste in the contract signed by the biodiesel operator and the restaurants; the location of the infrastructure supporting this biodiesel supply chain system; and whether biodiesel derived from kitchen waste can be part of sustainable energy solutions that are economically viable and environmentally acceptable.

\section{Model Construction}

4.1. Two-Stage Stochastic Programming Model. The objective of WCO for biodiesel supply chain stochastic programming model under supply disturbance is to minimize the expected total system cost and carbon emission cost by satisfying some constraints. This paper assumes that the kitchen waste supply by restaurants depends on two factors: (a) the proportion of kitchen waste supplied to biodiesel refineries and (b) the total supply of kitchen waste. Biodiesel refineries offer a group of prices per unit kitchen waste of restaurants and promise to buy the kitchen waste they provide. Under this commitment, the biodiesel refiners buy the kitchen waste at that price and then the restaurants supply a percentage of kitchen waste. As the purchase price increases, the percentage may increase. After the kitchen waste is collected, it is treated by a pretreatment facility established by the biodiesel refinery and transported to the biodiesel refinery. 


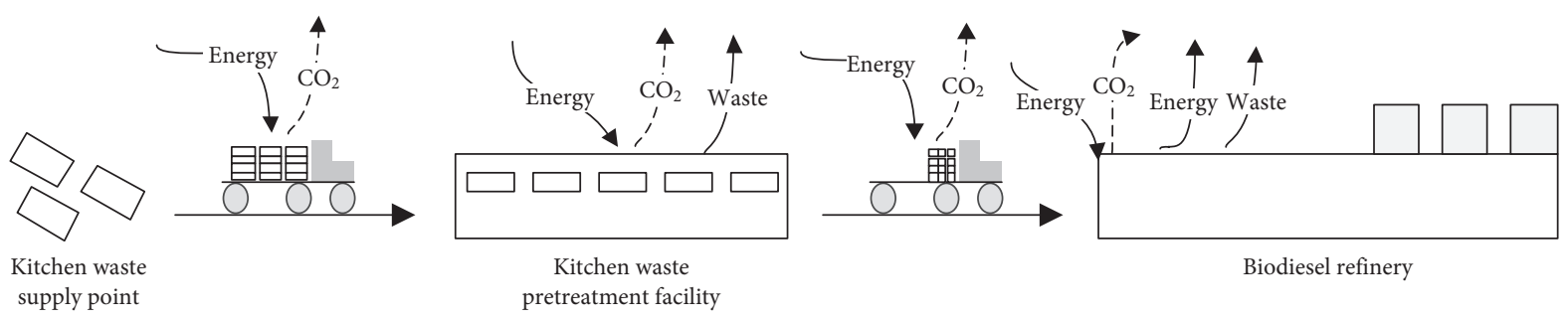

FIGURE 1: Waste cooking oil for biodiesel supply chain.

Pretreatment facilities pretreated kitchen waste from different kitchens and transported it to biodiesel refineries. Other assumptions include the following: (a) location of the pretreatment facility is determined by the biodiesel operator and selected from a set of known candidate sites; (b) biodiesel refineries need to process and convert the pretreated kitchen waste into biodiesel; (c) location of biodiesel refineries and demand for kitchen waste are deterministic; and (d) if the kitchen waste from the restaurants cannot meet the needs of the biodiesel refinery, the biodiesel operator needs to obtain it from an external supplier and there will be penalty charges for purchasing the unit's external kitchen waste. On the other hand, if the biodiesel operator has a surplus after meeting all the demand, it can sell the kitchen waste to make up for the loss of the excess raw materials.

In this paper, a scenario-based two-stage stochastic programming model is constructed. In the first stage, the location of the pretreatment facility and purchase price of the kitchen waste provided to the restaurants are determined. Then, based on the purchase price offered by the biodiesel operator, each restaurant decides how much kitchen waste allocates to biodiesel refineries for production. The total amount of kitchen waste was provided by each kitchen, which is influenced by random events such as the size of a city's population, consumption habits, and policy guidance. Supply uncertainty is addressed through a limited set of scenarios. When one scenario occurs, the total supply of the kitchen becomes known. In the second stage, the biodiesel refinery makes some decisions based on the calculated supply when the supply ratio and total supply are known. The decisions include the amount of kitchen waste transported from the restaurants to the pretreatment facility, the amount of kitchen waste transported from the pretreatment facility to the biodiesel refinery, the amount of kitchen waste purchased externally by each biodiesel operator, and the amount of excess kitchen waste to be sold. Under the standard two-stage stochastic programming model, the first-stage decision must be made before the actual system uncertainty is realized. After random events occur, decisions are made in the second stage. The goal of a typical two-stage programming model is to make decisions by minimizing the cost of the first stage and randomizing the expected cost of the second stage. A two-stage stochastic programming based on scenario divided uncertain spaces into countable scenarios, and each scenario is provided with a corresponding probability. Although scenario-based twostage stochastic programming sacrifices the solution's optimality, it ensures that the second-stage decision is made based on the occurrence of uncertainty. It is a good approximation of the total solution. Table 1 lists the symbols used in the model construction.

The two-stage stochastic programming model is expressed as follows:

$$
\begin{aligned}
& F_{1}=\operatorname{Min} \sum_{j \in J} f_{j} \times Y_{j}+E\left[\psi\left(Y_{j}, \pi, \Phi_{i}^{s}\right)\right], \\
& F_{2}=\operatorname{Min} \sum_{j \in J} e h_{j} \times Y_{j}+E\left[\chi\left(Y_{j}, \pi, \Phi_{i}^{s}\right)\right], \\
& \sum_{j \in J} M^{c} \times Y_{j} \geq \sum_{k \in K} \frac{D_{k}}{\mu} \\
& \qquad h \leq \pi \leq c \\
& Y_{j} \in\{0,1\}, \quad \forall j \in J .
\end{aligned}
$$

Specific to a given specific scenario:

$$
\begin{aligned}
\psi(s)= & \psi\left(Y_{j}, \pi, \Phi_{i}^{s}\right)=\operatorname{Min} \sum_{i \in I} \sum_{j \in J} c^{f d} \times q_{i j}^{s} \times d_{i j}+\sum_{j \in J} \sum_{k \in K} c^{w d} \times q_{j k}^{s} \times d_{j k} \\
& +\sum_{j \in J} \sum_{k \in K} \operatorname{CPR} \times q_{j k}^{s}+\sum_{s \in S} \sum_{i \in I} \Phi_{i}^{s} \times \pi \times \Gamma_{i}(\pi)+\sum_{k \in K} c \times Q_{j}^{s}-\sum_{i \in I} h \times W_{i}^{s}, \\
\chi(s)= & \chi\left(Y_{j}, \pi, \Phi_{i}^{s}\right)=\operatorname{Min} \sum_{i \in I} \sum_{j \in J} \operatorname{EHV} \times q_{i j}^{s}+\sum_{i \in I} \sum_{j \in J} \mathrm{ECT} \times q_{i j}^{s} \times d_{i j} \\
& +\sum_{j \in J} \sum_{k \in K} \mathrm{ECT} \times X_{j k}^{s} \times d_{j k}+\sum_{j \in J} \sum_{k \in K} \mathrm{EBD} \times q_{j k}^{s},
\end{aligned}
$$


Table 1: Description of symbols used in the base model.

\begin{tabular}{|c|c|}
\hline Set & \\
\hline$I$ & Set of kitchen waste supply points $i$ \\
\hline$J$ & Set of potential pretreatment facility locations $j$ \\
\hline$K$ & Set of biodiesel refinery locations $k$ \\
\hline$S$ & Set of uncertain scenarios $s$ \\
\hline Parameter & \\
\hline$\Gamma_{i}(\pi)$ & Function of the kitchen waste amount of supply point $i$ provided for the biodiesel operator according to the price $\pi$ \\
\hline$d_{i j}$ & Distance from supply point $i$ to pretreatment facility $j$ \\
\hline$d_{j k}$ & Distance from the pretreatment facility $j$ to the biodiesel refinery $k$ \\
\hline$\Phi_{i}^{s}$ & Total amount of annual kitchen waste supply in each supply point $i$ under scenario $s$ \\
\hline$f_{j}^{i}$ & Fixed construction cost of the pretreatment facility $j$ \\
\hline$p^{s}$ & Probability of scenario $s$ \\
\hline$C$ & Penalty fees for shortage demand of biodiesel \\
\hline$H$ & Residual value of excess kitchen waste \\
\hline$D_{k}$ & Demand for biodiesel at the biodiesel refinery $k$ \\
\hline$c^{f^{d} d}$ & Transport costs for kitchen waste by truck \\
\hline$c^{w d}$ & Transport costs for waste cooking oil by truck \\
\hline EHV & Carbon emissions from unit kitchen waste collection \\
\hline ECT & Carbon emissions from transportation by truck \\
\hline$M^{c}$ & Maximum processing capacity of the pretreatment facility \\
\hline$e h_{j}$ & Carbon emissions from the construction of pretreatment facility $j$ \\
\hline EBD & Carbon emissions from pretreatment facilities deal with unit kitchen waste \\
\hline $\mathrm{CPR}$ & Processing cost from unit kitchen waste at the pretreatment facility \\
\hline$\mu$ & Pretreatment rate of unit kitchen waste at pretreatment facility \\
\hline$\alpha$ & The weight \\
\hline CEP & Trading price from unit carbon emissions \\
\hline
\end{tabular}

Decision variables

\begin{tabular}{l}
$\begin{array}{r}\text { Quantity of kitchen waste from supply point } i \text { to pretreatment facility } j \text { in scenation } \\
q_{j \mathrm{k}}^{s} \\
Y_{j}^{s} \\
Q_{j}^{s} \\
W_{i}^{s} \\
\frac{\text { Quantity of waste cooking oil from pretreatment facility } j \text { to biodiesel refinery } k \text { in }}{1 \text { when location } j \text { is used to build a pretreatment facility, } 0 \text { otherwise }} \\
\text { Quantity of outsourcing kitchen waste at the pretreatment facility } j \text { in the situ } \\
\text { Quantity of excess kitchen waste at supply point } i \text { in scenario } s \\
\text { Negotiated purchase price for unit kitchen waste }\end{array}$ \\
\hline$F=\operatorname{Min} \alpha\left(\sum_{i \in I} \sum_{j \in J} c^{f d} \times q_{i j}^{s} \times d_{i j}+\sum_{j \in J} \sum_{k \in K} c^{w d} \times q_{j k}^{s} \times d_{j k}+\sum_{j \in J} \sum_{k \in K} \mathrm{CPR} \times q_{j k}^{s}\right.$ \\
$\left.+\sum_{s \in S} \sum_{i \in I} \Phi_{i}^{s} \times \pi \times \Gamma_{i}(\pi)+\sum_{j \in J} c \times Q_{j}^{s}-\sum_{i \in I} h \times W_{i}^{s}\right)+(1-\alpha)\left(\sum_{i \in I} \sum_{j \in J} \mathrm{EHV} \times q_{i j}^{s}\right.$ \\
$\left.+\sum_{i \in I} \sum_{j \in J} \mathrm{ECT} \times q_{i j}^{s} \times d_{i j}+\sum_{j \in J} \sum_{k \in K} \mathrm{ECT} \times X_{j k}^{s} \times d_{j k}+\sum_{j \in J} \sum_{k \in K} \mathrm{EBD} \times q_{j k}^{s}\right) \times \mathrm{CEP}$.
\end{tabular}

The objective functions $F_{1}$ and $F_{2}$ minimize the expected total cost and carbon emissions of the system, respectively. The objective function $F_{1}$ includes the cost of the first stage and the expected cost of the second stage. Operators $E_{\psi}$ represent mathematical expectations about random parameters $\psi(s)$. In objective function (1), the first-stage cost package is the fixed cost of the preprocessing facility construction, which is constant with the implementation of random parameters. The cost of the second stage depends on the scenario that is in formula (6): the transport cost of the biodiesel kitchen waste, the cost of the kitchen waste pretreatment facility, the purchase cost of the raw material kitchen waste, and the possible fuel shortage loss cost. Objective function (2) also includes the first stage cost and the second stage expected cost. Operators $E_{\chi}$ represent mathematical expectations about random parameters $\chi(s)$. The first stage of carbon emissions includes fixed carbon emissions from the construction of the pretreatment facility, the value of which is constant with the implementation of the random parameters. The second stage of carbon emissions is scenario-dependent in formula (7), including kitchen waste collection carbon emission, pretreatment carbon emission, and transport carbon emission. It is assumed that the cost function of raw material purchase has a piecewise linear relationship with the purchase quantity. For the calculation of carbon emissions, this paper mainly refers to the relevant carbon emission factor method. These factors are mainly calculated by quoting scholars' literature and 
some extrapolated data. Carbon emissions used in different processes are linear functions. The other constraint set is as follows:

$$
\begin{aligned}
& \sum_{i \in I} q_{i j}^{s} \leq M^{c} \times Y_{j}, \quad \forall j \in J, \\
& \mu \times\left(\sum_{i \in I} q_{i j}^{s}+Q_{j}^{s}\right)=\sum_{k \in K} q_{j k}^{s}, \quad \forall j \in J, \\
& \sum_{j \in J} q_{i j}^{s}+W_{i}^{s}=\Gamma_{i}(\pi) \times \Phi_{i}^{s}, \quad \forall i \in I, \\
& \sum_{j \in J} q_{j k}^{s} \geq D_{k}, \quad \forall k \in K, \\
& q_{i j}^{s}, q_{j k}^{s}, W_{i}^{s}, Q_{k}^{s} \geq 0 .
\end{aligned}
$$

Constraint (3) means that the total capacity of the pretreatment facility must be greater than the total demand of the system because all kitchen waste need transport passes through the pretreatment facility. Constraint (4) defines the lower and upper limits of unit kitchen waste purchase price. The purchase price of kitchen waste must be greater than the residual value and must be less than the penalty cost. If the kitchen waste purchase price is lower than the residual value, the biodiesel operator only needs to make a profit by selling the kitchen waste. Conversely, if the purchase price is higher than the unit penalty cost, the biodiesel operator can meet all demand by purchasing from an external supplier. Constraint (5) is a binary variable. Objective function (6) represents the economic cost throughout the whole supply chain. Objective function (7) represents carbon emission throughout the whole supply chain. Objective function (8) is the total cost after taking unit carbon emissions trading price into account. Constraint (9) is the capacity constraints of each pretreatment facility. Constraint (10) is the balance between the inflow and outflow of the pretreatment facility. Constraint (11) is the supply constraint that ensures that all supply is transported to biodiesel refineries. Constraint (12) biodiesel refineries meet a demand greater or equal to the total biodiesel demand. Since the objective function and the constraint condition both contain $\Phi_{i}^{s} \times \Gamma_{i}(\pi)$, the problems $\psi$ and $\chi$ change with different implementations of the random variable $\Phi_{i}^{s}$. For each first-stage decision, the problems $\psi$ and $\chi$ are feasible for all scenarios. Constraint (4) ensures that the capacity of kitchen waste transported through the pretreatment facility is sufficient so that all the pretreatment facility locations are feasible in the first stage. Biodiesel refineries can be outsourced to meet demand, so that the demand of each biodiesel refinery can always be outsourced regardless of the kitchen waste acquisition price and supply situation. Therefore, the properties of the mathematical model are largely dependent on $\Gamma_{i}(\pi)$.

\subsection{Stochastic Programming Model Reconstruction}

4.2.1. Allocation Decision Model for Restaurants. In order to determine the function $\Gamma$ introduced in the mathematical formula, it is necessary to take the restaurant's decision into consideration. A model which determines the relationship between the price and the supply proportion of kitchen waste is needed. In this paper, we followed the methods of Uster and Memişoğlu [35] and Memisoglu [36] to determine the relationship between the price and the supply proportion of kitchen waste. To form a hypothesis, restaurant makes a supply decision totally based on its expected profit. As a consequence, the kitchen uses the biodiesel operator if the expected profit is higher than the kitchen's current expected profit which is supplied to at least one other vendor. Suppose that restaurant $i$ provides kitchen waste $R_{i}$ to vendor $r$. The following symbols to construct the allocation decision model of the kitchen are shown in Table 2.

For each restaurant and vendor, the following equation must be followed:

$$
\operatorname{Sup}_{i r} \times \operatorname{Pep}_{r}-\operatorname{Ckp}_{i r}=\left(\operatorname{Sup}_{i^{*}} \times \operatorname{Bkp}_{i r}\right)-\operatorname{Ckp}_{i^{*}} .
$$

The left and right sides of equation (14), respectively, represent the expected unit profit (Yuan/year) that the restaurant provides to all vendors $r$ and the biodiesel operators. A kitchen will supply kitchen waste to a biodiesel operator only if its expected profit is greater than its expected profit from supplying at least one of the other vendors. For kitchen $i$, there is $\left|R_{i}\right|$ vendor demands, and therefore, there is $R_{i}$ balance price between the biodiesel operators, each represented by Bkp $\mathrm{Br}_{i r}$, where $r$ belongs to $R_{i}$. These prices can be determined by resolving (14) Bkp ${ }_{i r}$, which is a supplydemand balance price that can persuade restaurants to supply kitchen waste to biodiesel operators rather than to other vendors.

4.2.2. Reconstruction of Stochastic Programming Model of WCO for Biodiesel Supply Chain under Supply Disturbance. The optimal purchase price is one of the equilibrium prices of the restaurant's supply and demand. Thus, the set of continuous price values can be reduced to a set of discrete price points since each restaurant has a finite supply and demand equilibrium price. Let us define the set $\xi$, which represents all the supply and demand equilibrium prices $\xi=$ $\cup_{i, r} \rho_{i r}, \forall i \in I, r \in R_{i}$ for all the kitchens, and a new set $F \subseteq \xi$, representing all the possible different prices. $P_{f}$ is assumed to be a binary decision variable, $f \in F$; if the price $f$ is selected, then $P_{f}=1$; otherwise, it is 0 and $\pi_{f}$ is the relevant price value. $\omega_{i f}$ means that when the price $f$ is provided, the proportion of allocation $\omega_{i f}$ to the biodiesel operator determined by a kitchen $i$ is equal to $\Gamma_{i}\left(\pi_{f}\right)$ which can be calculated relatively easily. For each scenario, the cost of the biodiesel operator to purchase kitchen waste is a function $\pi_{f}$. 
TABLE 2: Description of the symbols used in the allocation decision model.

\begin{tabular}{lc}
\hline Symbol & Description \\
\hline $\operatorname{Sup}_{i r}$ & Quantity that $i$ expects to provide to vendor $r$ for kitchen waste purchase (tons/year) \\
$\operatorname{Pep}_{r}$ & Expected purchase price given by vendor $r$ (Yuan/ton) \\
$\mathrm{Ckp}_{i r}$ & Fees of restaurants $i$ providing kitchen waste to vendor $r$ (Yuan/year) \\
$\mathrm{Sup}_{i^{*}}$ & Quantity expected to be supplied by the restaurant $i$ to the biodiesel operator (tons/year) \\
$\mathrm{Bkp}_{i r}$ & The equilibrium price between supply and demand of restaurant $i$ and vendor $r$ (Yuan/ton) \\
$\mathrm{Ckp}_{i^{*}}$ & Fees for the provision of kitchen waste by restaurant $i$ to the biodiesel operator (Yuan/year) \\
\hline
\end{tabular}

The probability $p^{s}$ of each scenario is assumed to be known. Therefore, the purchase cost item can be extracted from the problems $\psi$ and $\chi$ and can be placed separately in the objective functions (1) and (2). According to these modifications, the model proposed in Section 4.1 is reconstructed as follows:

$$
\begin{gathered}
F_{1}=\operatorname{Min} \sum_{j \in J} f_{j} \times Y_{j}+\sum_{i \in I} \sum_{s \in S} \sum_{f \in F} \pi_{f} \times p^{s} \times P_{f} \times w_{i f} \times \Phi_{i}^{s}+E\left[\Delta\left(Y_{j}, P_{f}, \Phi_{i}^{s}\right)\right], \\
F_{2}=\operatorname{Min} \sum_{j \in J} e h_{j} \times Y_{j}+\sum_{i \in I} \sum_{s \in S} \sum_{f \in F} \operatorname{EHV} \times p^{s} \times P_{f} \times w_{i f} \times \Phi_{i}^{s}+E\left[\lambda\left(Y_{j}, P_{f}, \Phi_{i}^{s}\right)\right] .
\end{gathered}
$$

Subject to (3), (5) and the following:

For a given particular implementation, scenario $s$,

$$
\begin{gathered}
\sum_{f \in F} P_{f}=1, \\
P_{f} \in\{0,1\}, \quad \forall f \in F .
\end{gathered}
$$

$$
\begin{aligned}
& \Delta\left(Y_{j}, P_{f}, \Phi_{i}^{s}\right)=\operatorname{Min} \sum_{i \in I} \sum_{j \in J} \sum_{k \in K}\left(c^{f d} \times q_{i j}^{s} \times d_{i j}+c^{w d} \times q_{j k}^{s} \times d_{j k}\right)+\sum_{j \in J} \sum_{k \in K} \mathrm{CPR} \times q_{j k}^{s} \\
& +\sum_{j \in J} c \times Q_{j}^{s}-\sum_{i \in I} h \times W_{i}^{s} \\
& \lambda\left(Y_{j}, P_{f}, \Phi_{i}^{s}\right)=\operatorname{Min} \sum_{i \in I} \sum_{j \in J} \sum_{k \in K} \operatorname{ECT} \times\left(q_{i j}^{s} \times d_{i j}+q_{j k}^{s} \times d_{j k}\right)+\sum_{j \in J} \sum_{k \in K} \operatorname{EBD} \times q_{j k}^{s}, \\
& F=\operatorname{Min} \alpha \times\left(\sum_{j \in J} f_{j} \times Y_{j}+\sum_{i \in I} \sum_{s \in S} \sum_{f \in F} \pi_{f} \times p^{s} \times P_{f} \times w_{i f} \times \Phi_{i}^{s}+\sum_{i \in I} \sum_{j \in J} c^{f d} \times q_{i j}^{s} \times d_{i j}\right. \\
& \left.+\sum_{j \in J} \sum_{k \in K} c^{w d} \times q_{j k}^{s} \times d_{j k}+\sum_{j \in J} \sum_{k \in K} \mathrm{CPR} \times q_{j k}^{s}+\sum_{j \in J} c \times Q_{j}^{s}-\sum_{i \in I} h \times W_{i}^{s}\right)+(1-\alpha) \\
& \times\left(\sum_{j \in J} e h_{j} \times Y_{j}+\sum_{i \in I} \sum_{s \in S} \sum_{f \in F} \mathrm{EHV} \times p^{s} \times P_{f} \times w_{i f} \times \Phi_{i}^{s}+\sum_{i \in I} \sum_{j \in J} \mathrm{ECT} \times q_{i j}^{s} \times d_{i j}\right. \\
& \left.+\sum_{j \in J} \sum_{k \in K} \operatorname{ECT} \times q_{j k}^{s} \times d_{j k}+\sum_{j \in J} \sum_{k \in K} \operatorname{EBD} \times q_{j k}^{s}+\sum_{j \in J} e h_{j} Y_{j}\right) \times \mu .
\end{aligned}
$$


Subject to (9), (10), (12), and the following:

$$
\sum_{j \in J} X_{i j}^{s}+W_{i}^{s}=\sum_{f \in F} P_{f} \times \Phi_{i}^{s} \times w_{i f}, \quad \forall i \in I .
$$

In the reconstructing model, the first and second formulas of objective function (15) represent the total fixed cost and the expected acquisition cost, respectively. The first and second formulas in (16) represent carbon emissions during construction and collection, respectively. Constraint (4) no longer needs to be removed from the entire model, while constraints (17) and (18) are added to the new model, which ensure that only one of the supply and demand equilibrium prices is selected. At the same time, the overall problem with this new model becomes linear. Although the introduction of new binary variables $w_{i f}$ into this model increases the number of decision variables, it also reduces the pricing decision to a limited set of choices.

4.2.3. Solutions. Aiming at the economic and environmental objectives involved in the model, this paper introduces the environmental cost (carbon emission trading price), converts the environmental target into the economic cost target, and refers to the weight coefficient between the environmental target and the economic target value [37], so as to transform the multiobjective problem into a single-objective problem. Thus, the single-objective supply chain optimization model can be solved by MATLAB programming software. Combined with the solution idea of two-stage stochastic programming model, this paper introduces situational variables to transform the optimization model under certain conditions into stochastic programming model under uncertain conditions. The specific solution idea of the two stages is as shown in Figure 2 [36]:

Step 1: make a first-stage decision to determine the construction status of each pretreatment facility

Step 2: calculate the cost of the first stage

Step 3: at the beginning of the second phase, realize all the uncertain supplies

Step 4: at the end of the second stage, see the realization of uncertainty and the decision of the first stage, and make the second stage decision, namely, supply price and transportation volume

Step 5: calculate the scenario cost of the second stage

Step 6: calculate the expected total cost

In this article, according to different circumstances, supply points calculated the average supply of decision variables in the first phase of $Y_{j}$, whether to choose preprocessor facilities with value of 1 , then $Y_{j}$ value will not be affected by changes in supply, will also receive a preliminary objective function value, and corresponds to a suitable supply chain network structure. In order to get the optimal allocation decision, the decision of the second stage is needed. In this stage, a subproblem is generated according to each different supply situation. In each subproblem, the objective function is no longer a decision about the construction of pretreatment facilities, but a decision about the distribution of food and kitchen waste, that is, it determines $q_{i j}^{s}$ and $q_{j \mathrm{k}}^{s}$. Based on the sequential decision of location and distribution problems based on two-stage stochastic programming, the optimal design scheme of food waste supply chain network can be obtained.

\section{Case Analysis}

5.1. Disturbance Factors. The disturbance factor in the supply chain is the total supply of kitchen waste, and the specific calculation process is as follows: first, the supply quantity is estimated under the basic scenario. The case analysis in this section adopts the real data of the Yangtze River Delta region. It is assumed that the kitchens on the supply point of the kitchen waste in each city are clustered at the central position of the cities in the Yangtze River Delta. Then the geographic location and coordinates of the city centre are obtained through GIS as the location of the restaurants in the supply point. The calculation of the total supply of kitchen waste is estimated by the following equation [38]:

$$
M_{i}=\kappa_{i} \times \bar{M}
$$

where $\kappa_{i}$ is the population of city $i$ and $\bar{M}$ represents the annual production of kitchen waste per capita in China. In this paper, the statistical value of 2019 , namely, $0.18 \mathrm{~kg} /$ day person, is used to get the total quantity of kitchen waste supply in each city. However, within the scope of China, although Shanghai, Nanjing, Suzhou, and other cities have carried out the first practice of garbage recycling and achieved preliminary results, most of the recycling objects are only for the kitchen waste produced by catering enterprises and large canning rooms, while the recycling cost of household waste is relatively high. Some studies have shown that kitchen waste from enterprises and large dining room takes only about $25 \%$ of the total current kitchen waste output; therefore, the proportion of restaurant waste that can be recycled for the firms in current Yangtze normal situation all is set to $25 \%$. We concluded that the number of kitchen waste supply is used as a normal situation in this case in Table 3.

5.1.1. Determination of Kitchen Waste Supply Scenario. It can be seen from the data statistics in the previous section that people's increasing consumption in catering has brought about a rapid growth of kitchen waste. The government has introduced a series of measures to reduce the amount of kitchen waste. The Yangtze River Delta is also trying to introduce some policies to reduce the generation of kitchen waste, for example, "Empty Plate Campaign" and so on to encourage the moderate consumption. Considering the reduction policy on the influence of the amount of kitchen waste in this case study, we divided 10 classes according to $0.5 \%$ of the total recursive difference, respectively. Ten kinds of scenario have the same probability. Supply and geographical distribution of kitchen waste under standard circumstances are shown in Figure 3. 


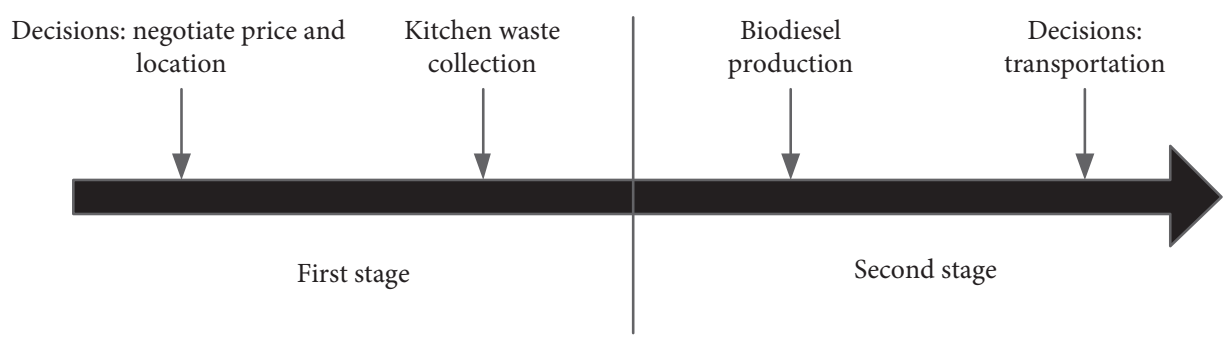

FIgURE 2: Solution idea of the two-stage stochastic programming model of WCO for biodiesel supply chain.

TABLE 3: Total supply of recyclable kitchen waste in the Yangtze River Delta.

\begin{tabular}{lc}
\hline Supply point & Quantity of food waste (tons) \\
\hline Shanghai & 396657 \\
Hefei & 127960.1 \\
Ma'anshan & 37155.23 \\
Hangzhou & 117533.6 \\
Ningbo & 95889.95 \\
Jiaxing & 57175.03 \\
Huzhou & 43329.95 \\
Shaoxing & 72772.1 \\
Zhoushan & 16003.03 \\
Wenzhou & 133643.4 \\
Jinhua & 78028.1 \\
Quzhou & 41983.9 \\
Taizhou (Zhejiang Province) & 98069.28 \\
Lishui & 43629.08 \\
Nanjing & 134946.7 \\
Wuxi & 106765.2 \\
Xuzhou & 141719.7 \\
Changzhou & 77130.73 \\
Suzhou & 174174.5 \\
Nantong & 119862.5 \\
Lianyungang & 73113.95 \\
Huaian & 79694.63 \\
Yancheng & 118644.6 \\
Yangzhou & 73541.28 \\
Zhenjiang & 52089.95 \\
Taizhou (Jiangsu province) & 76190.63 \\
Suqian & 79545.08 \\
\hline
\end{tabular}

\subsection{Deterministic Factors}

5.2.1. Proportion and Quantity Supplied to Biodiesel Refineries. In order to determine the proportion and quantity of kitchen waste supplied to biodiesel refineries, three directions of kitchen waste in Jiangsu Province in recent years should be determined first. According to the investigation, they are, respectively, gutter oil production, animal husbandry, and organic fertilizer production, and the vendors are represented by $r$. According to the survey data, the flow proportion of total kitchen waste in the Yangtze River Delta was determined, and the supply proportion of kitchen waste in each city was calculated. Then, according to the total 2018 kitchen waste in Yangtze River Delta, calculate the supply to the above three parties Sup $_{i r}$, in order to determine the kitchen waste purchase price of each demand point $r$, and this paper takes questionnaire investigation and gets the purchase price of all the demand point in 2016, 2017,

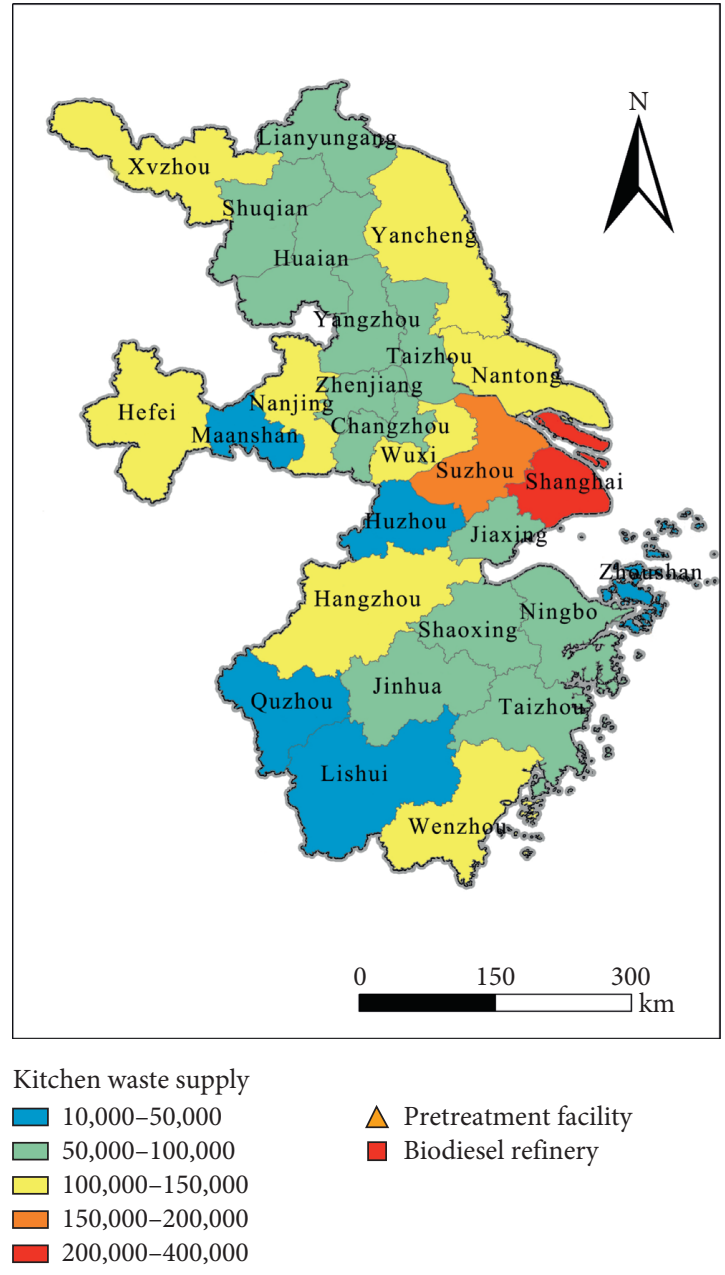

FIgURE 3: Supply of kitchen waste in the Yangtze River Delta under standard scenario.

and 2018. Then we determine the average value to the purchase price. For restaurants supply costs $\mathrm{Ckp}_{i r}$, the survey found when a restaurant supplies kitchen waste for cooking oil production and organic fertilizer production manufacturers, and kitchens need to do a series of garbage classification which is simple to handle, so the cost is relatively a bit higher which is about 50 Yuan/ton. While provided to livestock feed manufacturers, restaurants processing fee is very low, only artificial collection and handling are needed, so the cost is relatively low. Here we assumed that the kitchen waste supply fee $\mathrm{Ckp}_{i^{*}}$ is roughly the same as that of supply fee for gutter oil production, which is 
estimated to be 50 Yuan/ton. Then, the above parameters were substituted into equation (14) to find the supply-demand balance price $\mathrm{Bkp}_{i r}$ of kitchen waste supplied to biodiesel operators. These figures were corresponding to the break-even price $\left(\pi_{f}\right)$ in the model proposed in Section 4.

\subsubsection{Kitchen Waste Demand Point and Candidate Facility} Locations. Figure 4 shows the locations of candidate pretreatment facilities. After preliminary investigation, 27 prefecture-level cities can be listed as candidate cities for the construction of pretreatment facilities in the Yangtze River Delta. The geographic centre of each city is selected as the location coordinates of candidate pretreatment facilities and used in the case study.

The optimization of WCO for biodiesel supply chain aims at the process of biodiesel operators purchasing kitchen waste, so the location of the demand point here is the location of the demand point of kitchen waste, that is, the location of biodiesel refinery. Biodiesel production statistics website provides the list of the biological diesel oil refinery, and this paper chooses five large- and medium-sized biodiesel refining company according to the preliminary research as shown in Figure 4. They are Shanghai Jinshan Biological Diesel Co., Ltd., Hangzhou Xiaoshan Yuanhua Energy Technology Co., Ltd., Changzhou Yueda Carter New Energy Co., Ltd., and Jiangsu Clean Environment Co., Ltd. In order to determine the total demand of kitchen waste, this paper uses the company's annual report to estimate the demand for biodiesel of each company. According to the current biodiesel processing rate, calculations of total demand for kitchen waste are about 530,947 tons.

5.2.3. Other Parameters. There are other parameters in this paper, as shown in Table 4.

5.3. Result Analysis. In order to verify the model, the paper uses the actual data of the Yangtze River Delta region to conduct a case study. We first analyze the basic setting results of the standard parameter value, then change some parameter values, and analyze their effects on supply chain network design, total cost, and negotiated purchase price.

\subsubsection{Analysis of Facility Location under Stochastic} Programming. The above basic setting parameters are used here to obtain the optimal pretreatment facility location, as shown in Figure 5. Eight pretreatment facilities have been opened around the Yangtze River Delta. Four pretreatment facilities in the northwest and the middle of the Yangtze River Delta serve biodiesel refineries in Jiangsu and Anhui provinces. Another four pretreatment facilities opened in the south and east parts of the Yangtze River Delta serve biodiesel refineries in Zhejiang Province and Shanghai City.

The optimization results of the model show that the estimated total system cost is about 303.4096 million Yuan. Among them, more than half of the total system cost (about $46.8 \%$ ) is the fixed cost for the construction of pretreatment facilities and the purchase cost for buying kitchen waste.

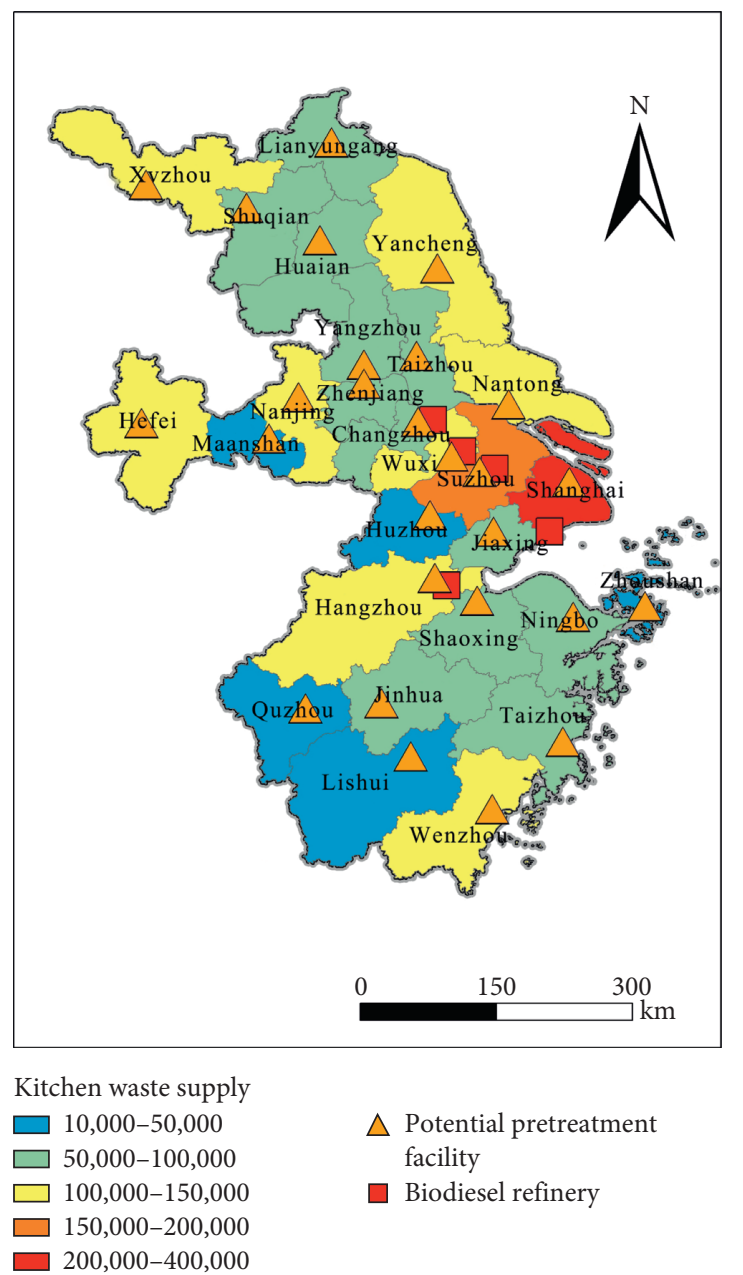

FIGURE 4: Location of alternative points of pretreatment facilities.

Most of the remaining expected cost is for transportation. The optimization results show that it is more economical to transport the kitchen waste from the middle part of the Yangtze River Delta where the supply is relatively high, to the middle part of the Yangtze River Delta where most of the demand occurs. It is better than to offer higher prices for the restaurant in the north and south of the Yangtze River Delta to provide a greater proportion of the kitchen waste to the biodiesel refineries. There is a trade-off between the purchase price of kitchen waste and the logistics cost in the system. The results of this section show that it is more economical to set a low purchase price for restaurants in the central part of the Yangtze River Delta to increase the proportion of kitchen waste supply than to transport kitchen waste supply from the north and south of the Yangtze River Delta to meet the demand.

5.3.2. Analysis of the Negotiated Purchase Price under the Base Scenario. Using the model proposed in Section 4, the optimal supply price is 348.2 Yuan/ton, and the supply ratio is shown in Table 5. At present, the purchase price of kitchen waste in the market is about 500 Yuan/ton. Therefore, biodiesel refineries under contract can not only guarantee 
TABLE 4: Other parameters.

\begin{tabular}{lc}
\hline Other parameters & Parameter value \\
\hline The conversion factor of kitchen waste to waste cooking oil & $7 \%$ \\
Preprocessing cost for unit kitchen waste & $15 \mathrm{Yuan} /$ ton [39] \\
Penalty fees for shortage demand of biodiesel & $700 \mathrm{Yuan} / \mathrm{ton}[40]$ \\
Disposal price of excess kitchen waste & $60 \mathrm{Yuan} /$ ton [41] \\
The distance transportation cost of unit kitchen waste & $0.20 \mathrm{Yuan} / \mathrm{ton} / \mathrm{km} \mathrm{[27]}$ \\
The distance transportation cost per unit of waste oil & $0.25 \mathrm{Yuan} / \mathrm{ton} / \mathrm{km} \mathrm{[42]}$ \\
The carbon emissions of unit kitchen waste collection & $5.6 \mathrm{~kg} \mathrm{CO} \mathrm{CO}_{2}$ eqv./ton [43] \\
The carbon emission of unit kitchen waste pretreatment & $12.6 \mathrm{~kg} \mathrm{CO} 2$ eqv./ton [44] \\
Carbon emissions from transportation & $0.1215 \mathrm{~kg} \mathrm{CO} \mathrm{CO}_{2}$ eqv./ton [43] \\
\hline
\end{tabular}

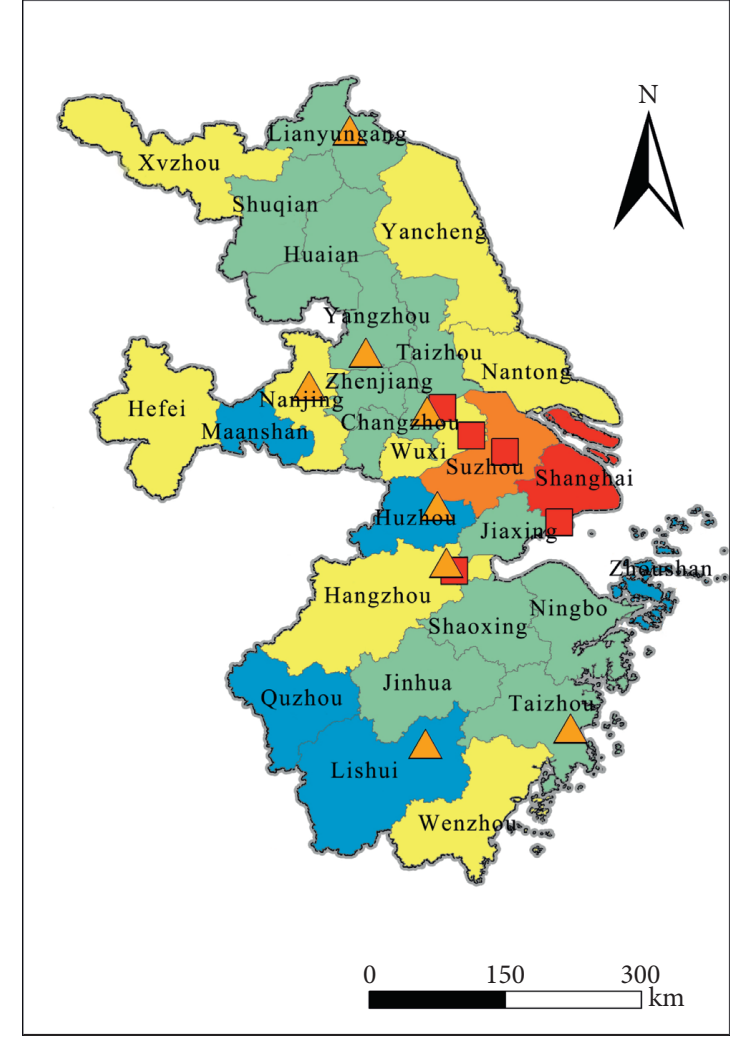

Kitchen waste supply

$\square$ 10,000-50,000
$\square$ 50,000-100,000
$\square$ 100,000-150,000
$\square$ 150,000-200,000
$\square$ 200,000-400,000

FIGURE 5: Optimization results of biodiesel supply chain in the collection stage under basic setting scenario.

the supply of kitchen waste, but also reduce the purchasing cost. At the same time, according to the calculation results, restaurants in Shanghai have the largest supply ratio according to the optimal price, with a supply ratio of $21.3 \%$. This ratio obviously does not meet the national goal of vigorously developing the kitchen waste recycling for biodiesel production. At the optimal price offered to restaurants (348.2 Yuan/ton), the Yangtze River Delta provided a total of $515,637.8$ tons of kitchen waste, which was lower than the total demand of 530,947 tons. In fact, in order to have a total
TABLE 5: Proportion of kitchen waste supply points in the Yangtze River Delta.

\begin{tabular}{lc}
\hline Supply point & Supply ratio \\
\hline Shanghai & 0.212979563 \\
Hefei & 0.204015776 \\
Maanshan & 0.19505199 \\
Hangzhou & 0.204015776 \\
Ningbo & 0.19505199 \\
Jiaxing & 0.186088204 \\
Huzhou & 0.177124417 \\
Shaoxing & 0.19505199 \\
Zhoushan & 0.177124417 \\
Wenzhou & 0.19505199 \\
Jinhua & 0.186088204 \\
Quzhou & 0.177124417 \\
Taizhou (Zhejiang Province) & 0.186088204 \\
Lishui & 0.177124417 \\
Nanjing & 0.204015776 \\
Wuxi & 0.19505199 \\
Xuzhou (Jiangsu Province) & 0.186088204 \\
Changzhou & 0.19505199 \\
Suzhou & 0.19505199 \\
Nantong & 0.186088204 \\
Lianyungang & 0.177124417 \\
Huaian & 0.177124417 \\
Yancheng & 0.177124417 \\
Yangzhou & 0.186088204 \\
Zhenjiang & 0.186088204 \\
Taizhou & 0.186088204 \\
Suqian & 0.177124417 \\
\hline
\end{tabular}

expected supply of about 530,947 tons of kitchen waste, the price should be set at 350 Yuan/ton.

5.3.3. Sensitivity Analysis. This section mainly analyses the difference in pricing decisions and supply chain network structure by changing the value of parameters. This is done by changing the value of one input parameter in the base scenario and keeping the others at their standard values, to generate four scenarios as shown in Table 6. In the first scenario $\left(S_{1}\right)$, the unit kitchen waste transportation cost is changed. In the second scenario $\left(S_{2}\right)$, the pretreatment rate of kitchen waste is changed. In the third scenario $\left(S_{3}\right)$, the residual value price per unit of food waste is changed, and finally, in the fourth scenario $\left(S_{4}\right)$, the unit penalty fee is changed when demand is insufficient [36]. 
TABLE 6: Setting of sensitivity analysis.

\begin{tabular}{|c|c|c|c|c|}
\hline Scenario & $S_{1}$ & $S_{2}$ & $S_{3}$ & $S_{4}$ \\
\hline Transportation cost (Yuan/ton/km) & $0.14-0.26$ & 0.2 & 0.2 & 0.2 \\
\hline Pretreatment rate of kitchen waste (\%) & 0.07 & $0.055-0.085$ & 0.07 & 0.07 \\
\hline Kitchen waste residual value (Yuan/ton) & 60 & 60 & 60 & $0-120$ \\
\hline Penalty fee (Yuan/ton) & 700 & 700 & $400-1,000$ & 700 \\
\hline
\end{tabular}

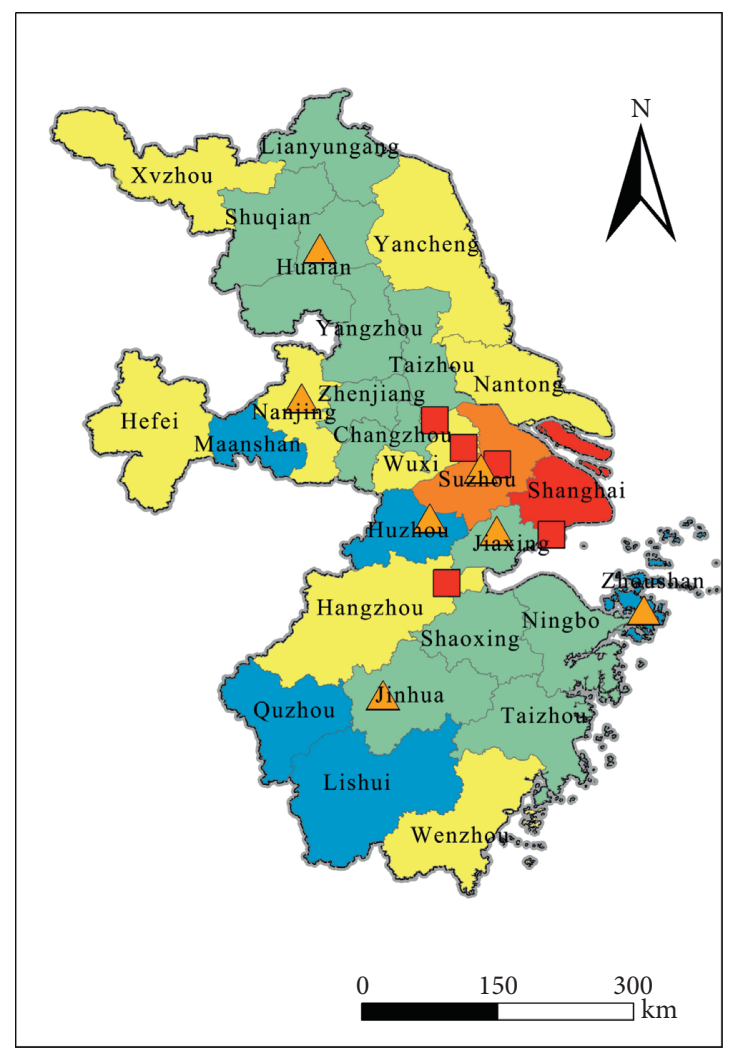

Kitchen waste supply

$\square 10,000-50,000$
$\square 0,000-100,000$
$\square 100,000-150,000$
$\square 00,000-200,000$
$200,000-400,000$

\begin{abstract}
$\triangle$ Pretreatment facility
Biodiesel refinery
\end{abstract}

(a)

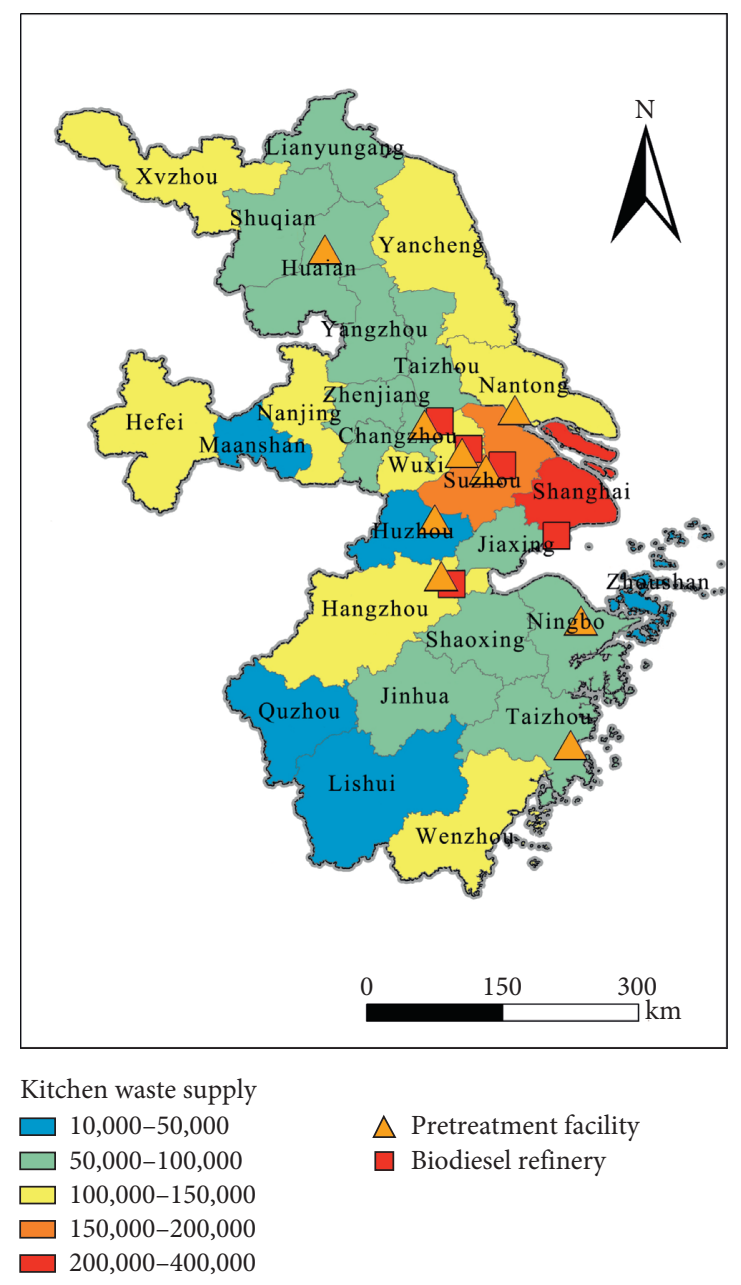

(b)

Figure 6: Network structure sensitivity analysis of penalty fee. (a) Penalty fee of 400 Yuan/ton. (b) Penalty fee of 1000 Yuan/ton.

(1) Sensitivity Analysis of Transportation Costs $S_{1}$. This scenario analyses different unit transportation cost systems ranging from 0.14 Yuan/ton-km to 0.26 Yuan/ton-km. As can be seen from Figure 6(a), for unit transportation cost ranging from 0.14 Yuan/ton-km to 0.24 Yuan/ton-km, the optimal purchase price is determined to be $348.2 \mathrm{Yuan} / \mathrm{ton}$, which is the same as the basic scenario result. However, for a higher unit transport charge, that is, 0.26 Yuan/ton-km, the best purchase price offered to kitchens dropped to 325.5 Yuan/ton $\mathrm{km}$. The main reason behind the change is that as unit transport costs increase, it becomes less economical for restaurants in distant locations to meet the biodiesel refineries demand. In other words, it becomes more economical for biodiesel refiners to choose to outsource rather than pay high logistics costs to meet demand. As a result, the price of food waste will be lower and the expected supply will be reduced. Pretreatment facility decisions are also affected when unit transportation costs change.

Figures 7(a) and 7(b) show the network structure when the unit transportation cost is 0.14 Yuan/ton- $\mathrm{km}$ and 0.26 Yuan/ton-km.

For lower unit transportation cost, we can see that the supply chain system has fewer preprocessing facilities. The increase in the number of pretreatment facilities (from 7 to 9) is in line with the increase in unit transport costs. That means biodiesel refineries need to open pretreatment facilities in more dispersed locations to reduce the increase in transport costs. Although restaurants are less able to meet 


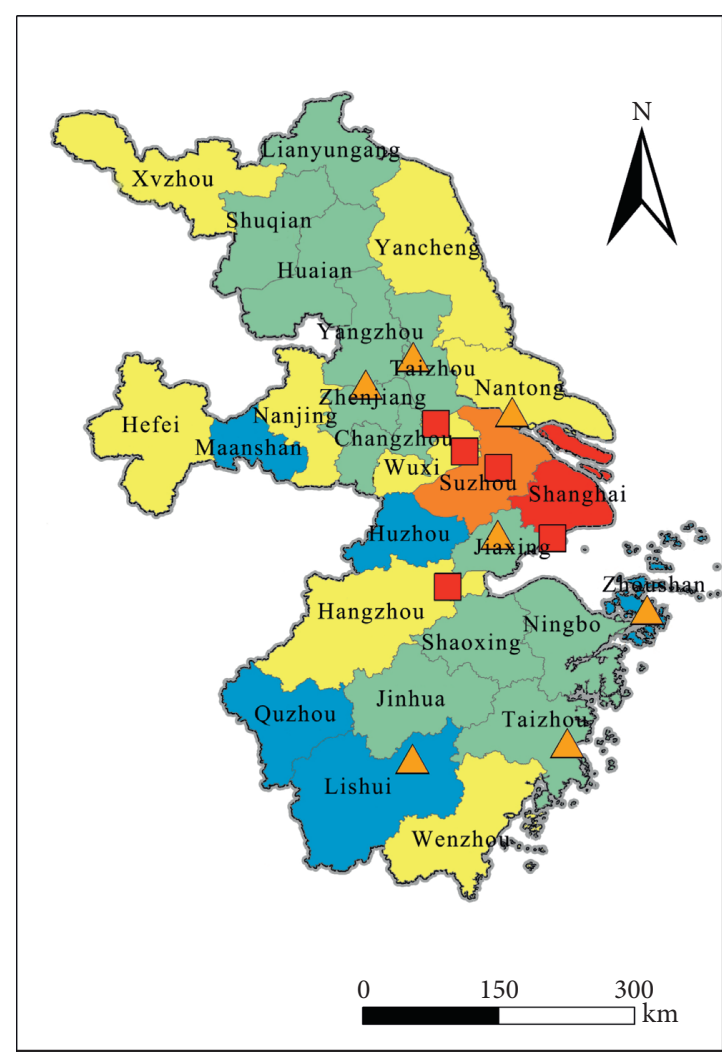

Kitchen waste supply
$\square$ 10,000-50,000
$\square 0,000-100,000$
$\square 100,000-150,000$
$\square 150,000-200,000$
$200,000-400,000$ $\triangle$ Pretreatment facility

$\square$ Biodiesel refinery

(a)

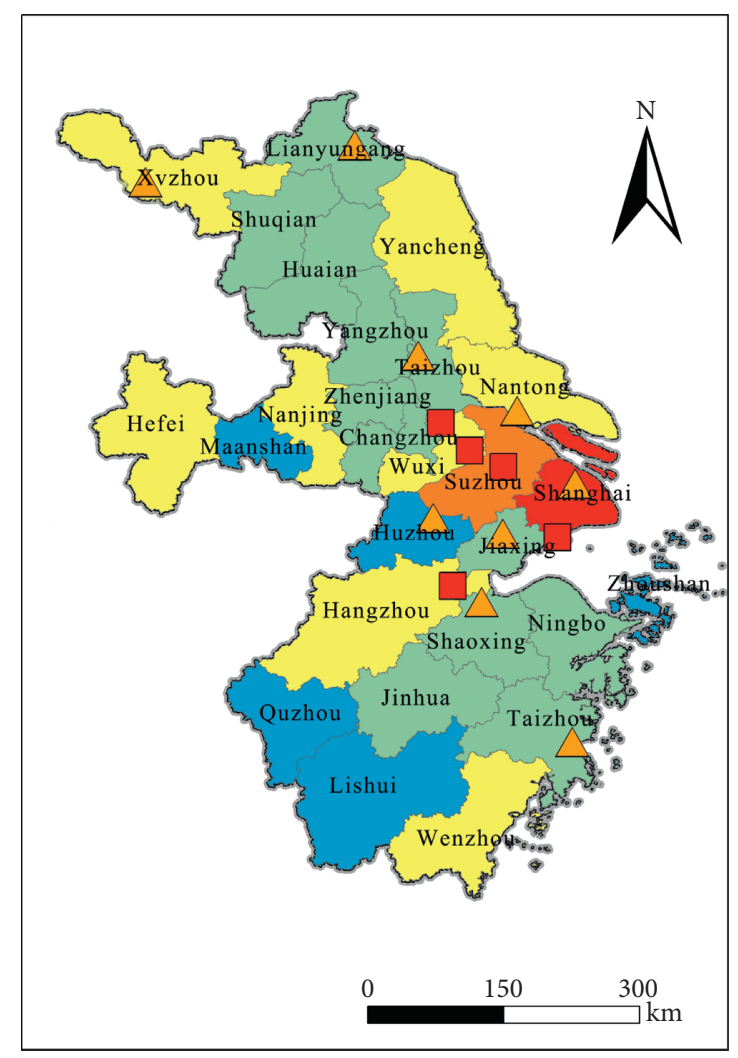

Kitchen waste supply

$\square 10,000-50,000$

$\square 50,000-100,000$

$\square 100,000-150,000$

$\square 150,000-200,000$

200,000-400,000

(b)

FIGURE 7: Network structure sensitivity analysis of transportation cost. (a) Transport cost of 0.14 Yuan/ton-km. (b) Transport cost of 0.26 Yuan/ton-km.

demand due to lower prices for kitchen waste, more pretreatment facilities have been opened to increase the supply of pretreated kitchen waste for transporting to biodiesel refineries. As shown in Figure 8(a), the estimated total system cost gradually increases as the unit transportation cost increases. When the unit transportation cost is from 0.14 Yuan/ton- $\mathrm{km}$ to $0.26 \mathrm{Yuan} / \mathrm{ton}-\mathrm{km}$, the expected total system cost will increase by about $7 \%$. That indicates the logistics cost has some impact on the expected total system cost.

(2) Sensitivity Analysis of Kitchen Waste Pretreatment Rate $S_{2}$. This scenario is mainly to analyse the sensitivity of kitchen waste pretreatment rate. Considering different kitchen waste pretreatment rates ranging from 5.5\% to $8.5 \%$, we observed the change in negotiated purchase price and network structure. The results show that, with the change in the pretreatment rate of kitchen waste, the purchase price provided to kitchens does not change basically (except for a small increase in 1 case), as shown in Figure 9(b). For all the kitchen waste pretreatment rates considered, the price remains the same as the basic scenario result, that is, 348.2
Yuan/ton. This indicates that the current range of kitchen waste pretreatment rate has no significant impact on the negotiated purchase price of kitchen waste. However, with the change of kitchen waste pretreatment rate, the structure of supply chain network has changed greatly. The paper found that, with the increase of kitchen waste pretreatment rate, pretreatment facilities opened decreased from 9 to 5 , because increase in the rate of pretreatment compared with previous less eat hutch garbage can meet the demand, so biodiesel operators choose to reduce the number of facilities built pretreatment, in order to reduce building and operating costs. In addition, it can be observed from Figures 10 (a) and $10(\mathrm{~b})$ that after the pretreatment rate is improved, the location of pretreatment changes from the original area with small population and small food waste supply to the area with large supply and large population, which improves the overall supply chain efficiency. Figure $8(\mathrm{~b})$ shows the relationship between the discount factor for economies of scale and the expected total system cost. Obviously, with the increase of the kitchen waste pretreatment rate, because the same amount of raw materials 


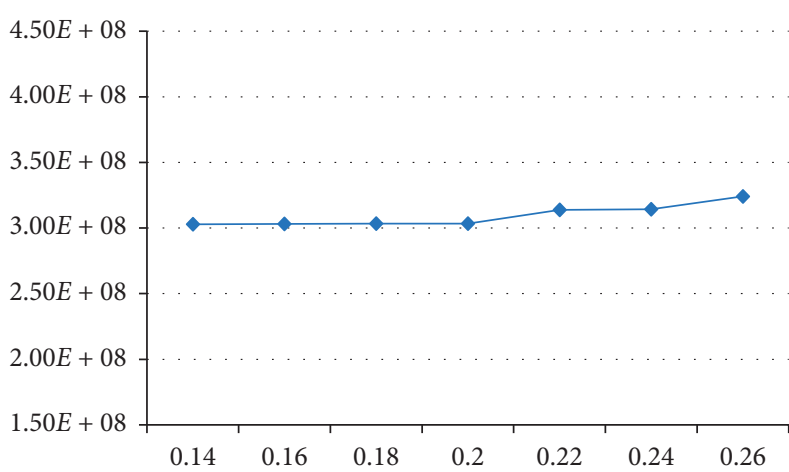

(a)

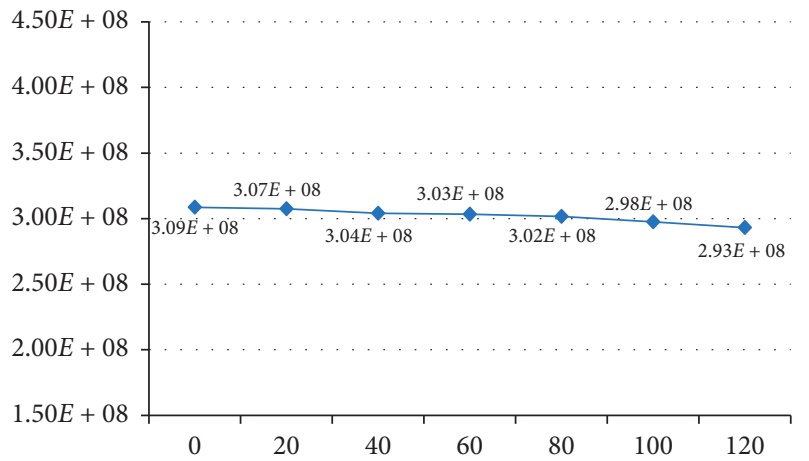

(c)

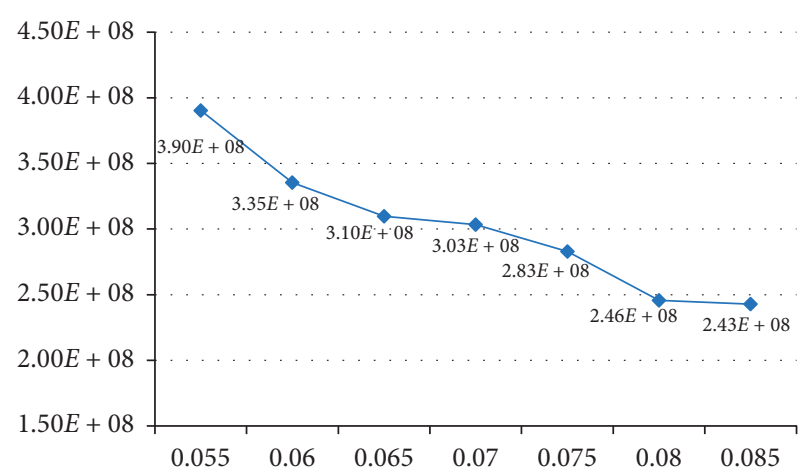

(b)

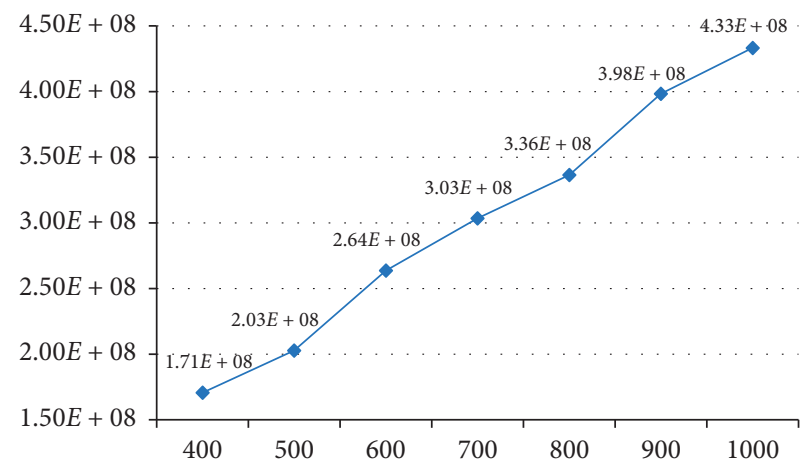

(d)

Figure 8: Influence of parameter values on the expected total system cost. (a) Transportation cost (Yuan/ton-km). (b) Pretreatment rate of kitchen waste. (c) Residual value of kitchen waste (Yuan/ton). (d) Penalty cost (Yuan/ton).

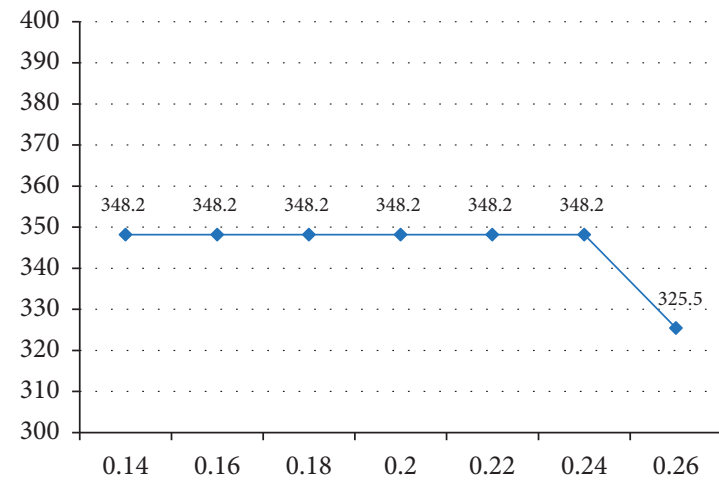

(a)

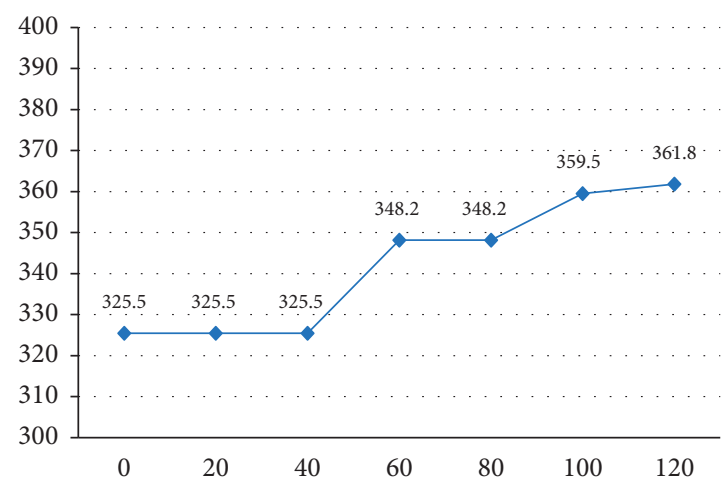

(c)

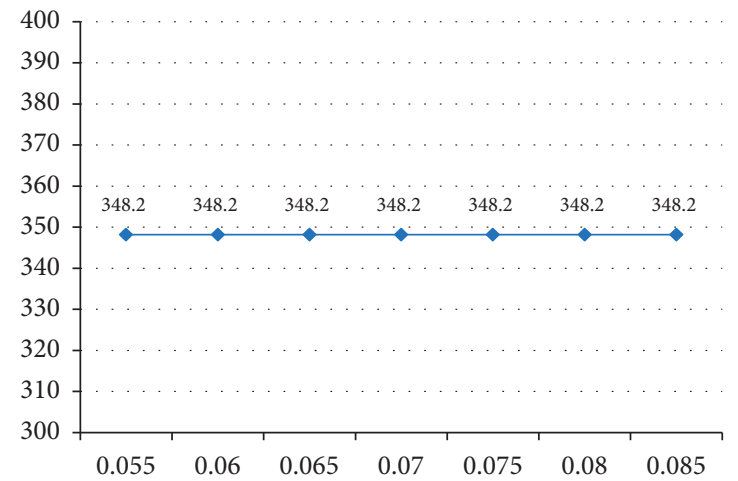

(b)

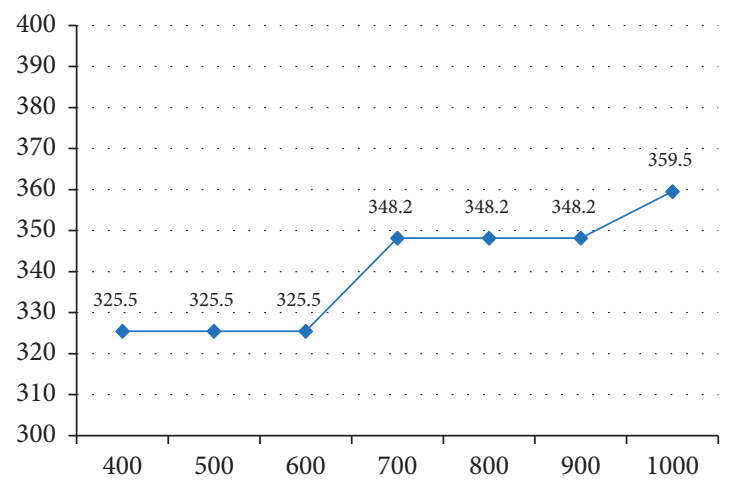

(d)

Figure 9: Influence of parameter values on price. (a) Transportation costs (Yuan/ton-km). (b) Pretreatment rate of kitchen waste. (c) Residual value of kitchen waste (Yuan/ton). (d) Penalty fee (Yuan/ton). 


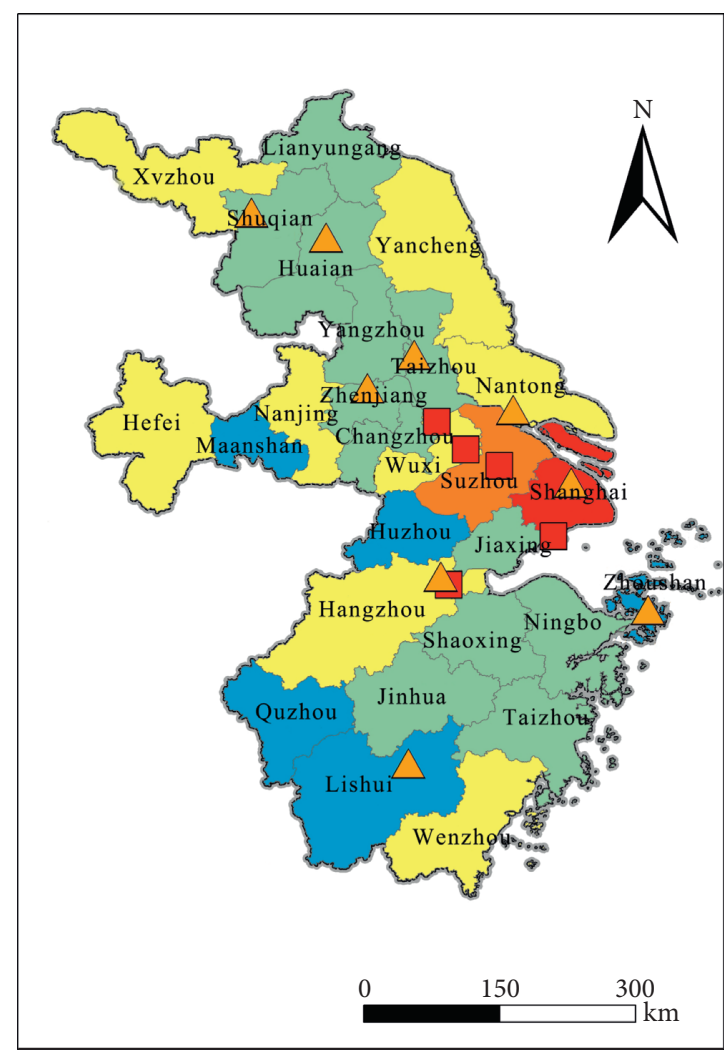

Kitchen waste supply
$\square$ 10,000-50,000
$\square 0,000-100,000$
$\square 100,000-150,000$
$150,000-200,000$
$200,000-400,000$ $\triangle$ Pretreatment facility

$\square$ Biodiesel refinery

(a)

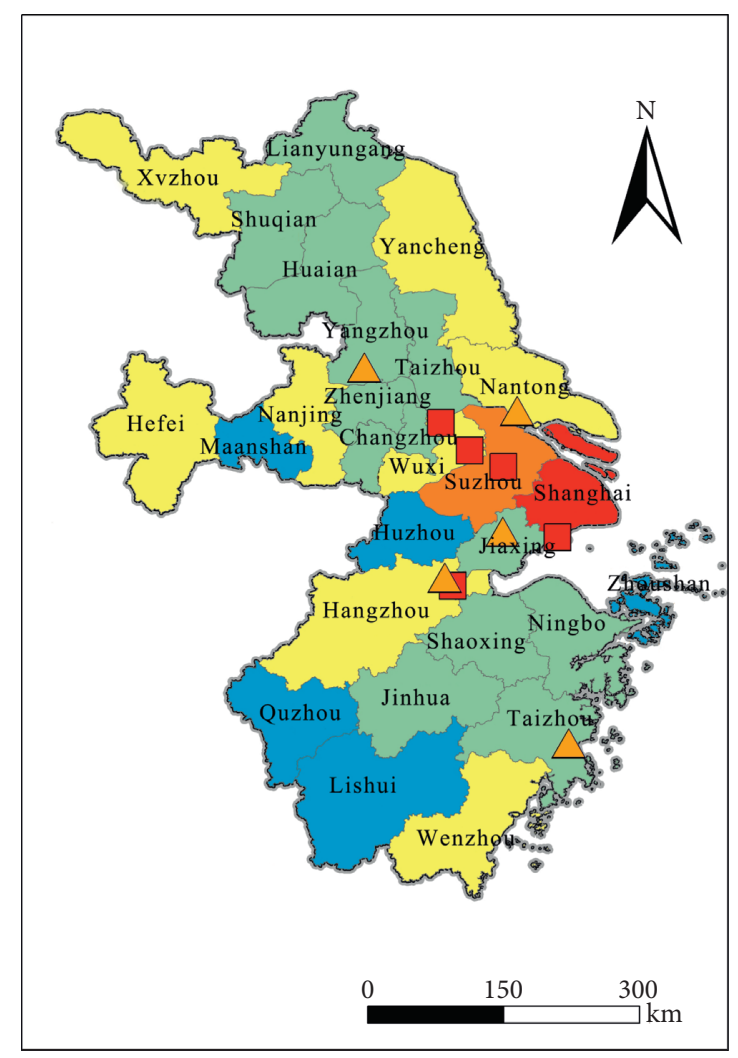

Kitchen waste supply

$\square$ 10,000-50,000

$\square 50,000-100,000$

$\square 100,000-150,000$

$\square 150,000-200,000$

$\square 200,000-400,000$

(b)

FIGURE 10: Network structure sensitivity analysis of kitchen waste pretreatment rate. (a) Pretreatment rate of 5.5\%. (b) Transportation rate of $8.5 \%$.

can produce more products, the expected total system cost is reduced, and the reduction is very significant. For example, when the increase in the kitchen waste pretreatment rate is doubled from its baseline pretreatment rate, the expected total system cost is reduced by nearly $25 \%$. Therefore, it can be considered that the pretreatment rate of kitchen waste has a significant impact on the expected total system cost.

(3) Sensitivity Analysis of Kitchen Waste Residual Value $S_{3}$. This scenario mainly analyses the influence of unit surplus kitchen waste residual value. Considering different residual values, ranging from 0 Yuan/ton to 120 Yuan/ton, the paper observes the impact on the first phase decision and the expected total system cost. When the residual value per unit is 0 Yuan/ton, the biodiesel refinery will not generate any revenue by selling excess kitchen waste. Figure 9(c) shows how the negotiated purchase price varies for different residual values. When the kitchen waste residual value is 0 Yuan/ton, 20 Yuan/ton, and 40 Yuan/ton, the negotiated purchase price is $325.5 \mathrm{Yuan} / \mathrm{ton}$, which is lower than the price of basic settings. When the unit salvage value price is between 40 Yuan/ton and 80 Yuan/ton, the optimal purchase price is 348.2 Yuan/ton. On the other hand, when the unit residual value price is $120 \mathrm{Yuan} /$ ton, the purchase price of kitchen waste rises to $361.8 \mathrm{Yuan} /$ ton. Therefore, the results show that as the unit residual value price increases, the negotiated price offered by biodiesel refineries to kitchens increases. The main reason for this result is that, with the rise in unit residual value prices, the income from the supply of excess kitchen waste increases. This incentivizes biodiesel operators to offer higher negotiated price to kitchens since the loss of excess kitchen waste can be compensated through residual values. Figures 11(a) and 11(b) show the optimal pretreatment facility decision when unit residual value is 0 Yuan/ton and 120 Yuan/ton, respectively. With the change of unit residual value, it was observed that the total number of pretreatment facility decisions (all are eight) and geographical distribution did not change, so it could be considered that unit residual value price had no significant influence on the decision of pretreatment facility. The relationship between unit residual value and the expected total system cost is shown in Figure $8(\mathrm{c})$. As the residual value goes up, the expected 


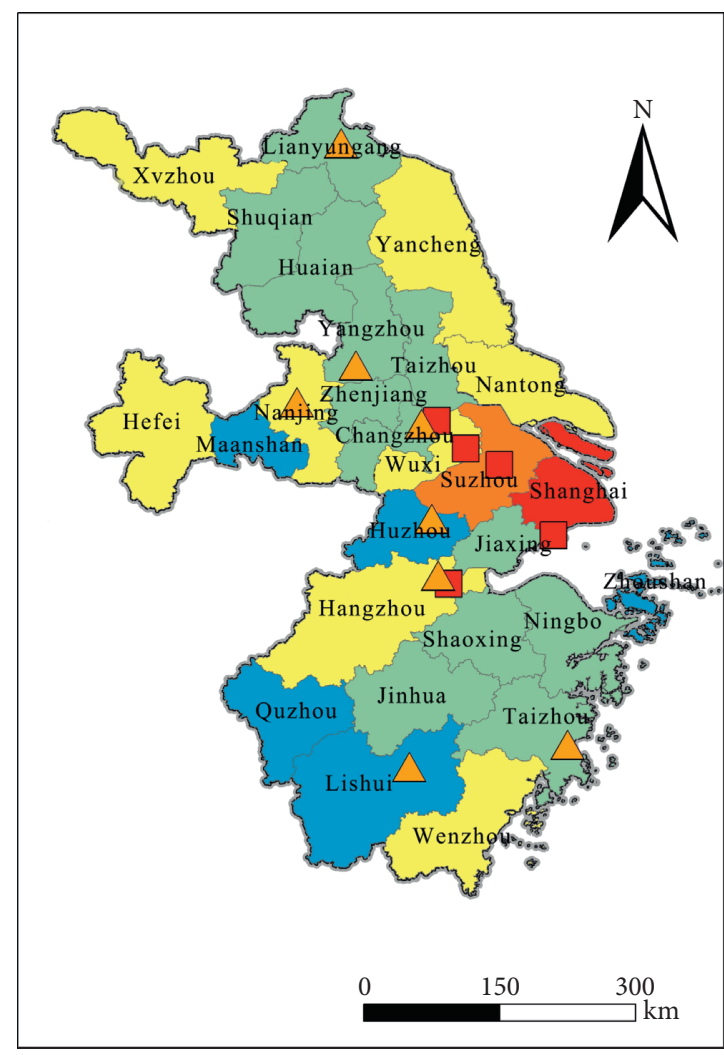

Kitchen waste supply

$\square 10,000-50,000$
$\square 0,000-100,000$
$\square 100,000-150,000$
$\square 150,000-200,000$
$200,000-400,000$

$\triangle$ Pretreatment facility

$\square$ Biodiesel refinery

(a)

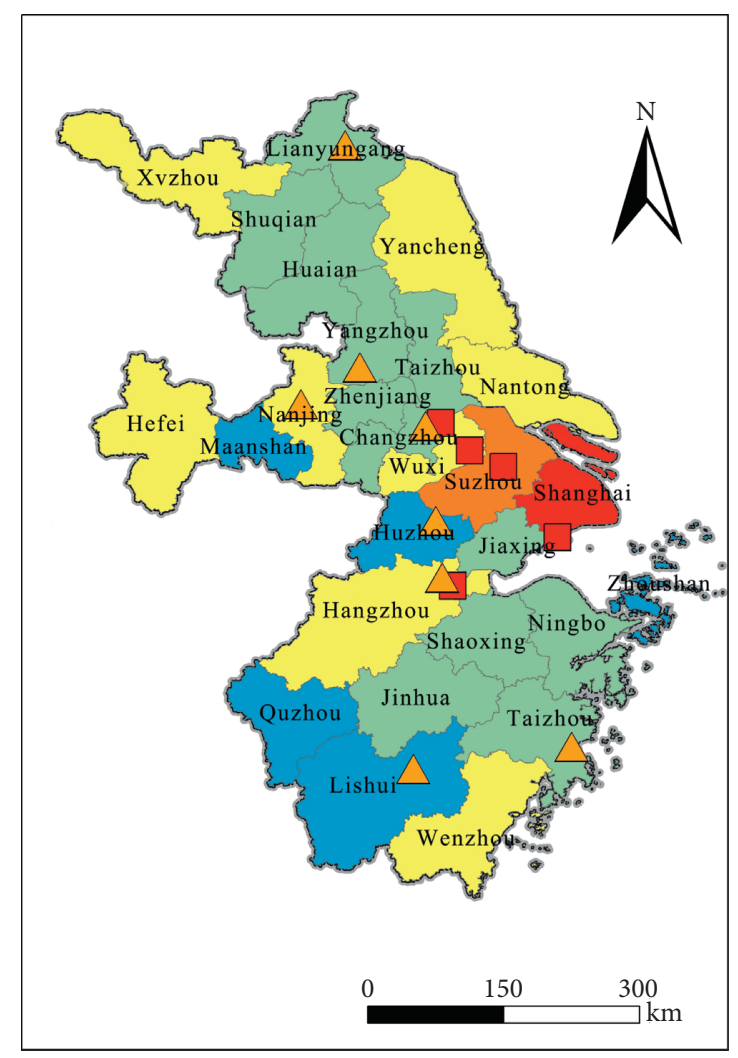

Kitchen waste supply

$\square 10,000-50,000$

$\square 50,000-100,000$

$\square 100,000-150,000$

$\square 150,000-200,000$

$\square 200,000-400,000$

(b)

FIGURE 11: Network structure sensitivity analysis of kitchen waste residual value. (a) Residual value of 0 Yuan/ton. (b) Residual value of 120 Yuan/ton.

reduction in total system cost is not significant. For example, when the unit residual value price increases by a factor of two from its nominal value, the expected total system cost decreases by only $3.4 \%$.

(4) Sensitivity Analysis of Penalty Fee $S_{4}$. This scenario takes into account variations in negotiated price, pretreatment facilities location, and expected total system costs at different unit penalty fee in the range from 400 Yuan/ton to $1000 \mathrm{Yuan} / \mathrm{ton}$.

Figure 9(d) shows how the negotiated price varies with the changes in penalty fee. With the increase of unit penalty fee, the purchase price of kitchen waste increases sharply. When the unit penalty fee is 400 Yuan/ton, 500 Yuan/ton, and $600 \mathrm{Yuan} / \mathrm{ton}$, the purchase price of kitchen waste is $325.2 \mathrm{Yuan} / \mathrm{ton}$, which is lower than the optimal purchase price obtained in the basic scenario. However, when the unit penalty fee is 1000 Yuan/ton, the best purchase price offered to restaurants is increased to $359.5 \mathrm{Yuan} / \mathrm{ton}$. This is because for a low penalty price, the logistics cost is greater than the penalty cost, and the biodiesel operator would rather choose other vendors to buy a certain amount of kitchen waste and pay the penalty, rather than spend more money to meet the needs of individual restaurants. With the increase in unit penalty fees, biodiesel operators find it too costly to obtain biomass from other sources; therefore, they choose restaurants and offer a higher purchase price to capture more of the expected kitchen waste. There is a trade-off between the purchase price of kitchen waste and the punish fee.

Low purchase prices lead to low supply of kitchens, which in turn affects decisions at preprocessing facilities. Figure 6(a) and 6(b) show the location of the optimal pretreatment facility when the unit penalty cost is 400 Yuan/ ton and 1000 Yuan/ton, respectively. When the unit penalty fee is 400 Yuan/ton, 7 pretreatment facilities need to be opened. With low expected supply and penalty costs, biodiesel operators can outsource their demand, and thus the demand for pretreatment facilities is reducing for. As the penalty fee increases, especially when the penalty fee increased to 1000 Yuan/ton, 9 pretreatment facilities need to be opened, and the orange area in the central part of the Yangtze River Delta pretreatment facilities increased by 2; they are Changzhou and Nantong. The two increased 
pretreatment facilities in the region of the position are closer to area with high supply. The reason is the area with high supply kitchens open pretreatment facilities become more economic with the increase in the penalty fee. In this way, the refinery can get more kitchen waste supply and reduce the punishment cost. The relationship between unit penalty costs and expected total system costs is shown in Figure 8(d). The results show that as the unit penalty cost increases, the expected total system cost also increases in a very significant way. When the unit penalty cost increases by two times from its nominal value, the expected total system cost increases by $39 \%$. At the same time, the curve can be understood as follows: When biodiesel operators are in insufficient demand, the punishment cost increases obviously. If the operators want to reduce total penalty cost, the out-of-stock rate needs to be decreased. So, the operators have to increase prices and purchase more raw materials on the basis of the original plant ensuring meeting production demand and reducing the punishment cost caused by shortage.

Figures 8 and 9, respectively, show the impact of these parameters on the price and expected total system cost.

\section{Conclusion}

In this paper, a stochastic programming model is proposed to optimize the WCO for biodiesel supply chain. The model proposed a system solution, which is a contract signed by the biodiesel operator and the restaurant to determine the purchase price and ensure the supply of kitchen waste. In order to incorporate this solution into the supply chain model, this paper presents an allocation decision model, which includes the relationship between the price of kitchen waste and the supply ratio. Then, a two-stage linear stochastic programming model was reconstructed by combining the restaurant's allocation decision model with the original supply chain model. At the same time, the influence of the kitchen waste supply uncertainty was considered, and the biodiesel supply chain network under disturbance was designed. This paper uses the actual data of the Yangtze River Delta region to conduct a case study to test the feasibility of the model. The results of the research in the basic scenario show that when the optimal purchase price provided by the biodiesel operator is set at 350 Yuan/ ton, the restaurant can guarantee the amount of kitchen waste required by the biodiesel refinery, and the price is lower than the market price. By sensitivity analysis, the results show that the unit penalty fee and the residual value of kitchen waste have significant effects on the purchase price. The unit transportation cost will affect the network structure of supply chain. The variation of unit penalty fee and kitchen waste pretreatment rate has a significant impact on the network structure and the expected total cost of the system.

\section{Data Availability}

All data generated or analysed during this study are included within this article.

\section{Conflicts of Interest}

The authors declare no conflicts of interest.

\section{Acknowledgments}

This work was supported by the Nanjing University of Posts and Telecommunications Research Start-Up Fund (NY219168), the Nature Foundation Incubation Fund of Nanjing University of Posts and Telecommunications (NY220214), the Project of Philosophy and Social Science Research in Colleges and Universities in Jiangsu Province (TJZ220011), and the Jiangsu Innovation Program for Graduate Education (KYLX15_0312).

\section{References}

[1] S. Ishak and A. Kamari, "Biodiesel from black soldier fly larvae grown on restaurant kitchen waste," Environmental Chemistry Letters, vol. 17, no. 2, pp. 1143-1150, 2019.

[2] S. Khan, M. Raza, A. Nosheen, R. Naz, S. M. U. Shah, and M. N. Hassan, "Quality comparison of biodiesel produced from waste cooking oil of restaurant and domestic kitchen," International Journal of Green Energy, vol. 17, no. 1, pp. 94$100,2020$.

[3] N. Geng, Y. Zhang, and Y. Sun, "A coordinating strategy for biofuel supply chain under disturbance using revenue sharing contract approach," PROMET-Traffic\&Transportation, vol. 30, no. 2, pp. 195-204, 2018.

[4] L. V. Snyder, "Facility location under uncertainty: a review," IIE Transactions, vol. 38, no. 7, pp. 547-564, 2006.

[5] S. M. Zahraee, N. Shiwakoti, P. Stasinopoulos, and S. Peter, "Biomass supply chain environmental and socio-economic analysis: 40-years comprehensive review of methods, decision issues, sustainability challenges, and the way forward," Biomass and Bioenergy, vol. 142, Article ID 105777, 2020.

[6] S. Giarola, A. Zamboni, and F. Bezzo, "Environmentally conscious capacity planning and technology selection for bioethanol supply chains," Renewable Energy, vol. 43, pp. 61-72, 2012.

[7] A. Osmani and J. Zhang, "Stochastic optimization of a multifeedstock lignocellulosic-based bioethanol supply chain under multiple uncertainties," Energy, vol. 59, pp. 157-172, 2013.

[8] B. Sharma, R. G. Ingalls, C. L. Jones, and A. Khanchi, "Biomass supply chain design and analysis: basis, overview, modeling, challenges, and future," Renewable and Sustainable Energy Reviews, vol. 24, no. 10, pp. 608-627, 2013.

[9] M. Langholtz, E. Webb, B. L. Preston et al., "Climate risk management for the U.S. cellulosic biofuels supply chain," Climate Risk Management, vol. 3, pp. 96-115, 2014.

[10] D. H. Nguyen and H. Chen, "Supplier selection and operation planning in biomass supply chains with supply uncertainty," Computers \& Chemical Engineering, vol. 118, pp. 103-117, 2018.

[11] B. Hu and Y. Feng, "Optimization and coordination of supply chain with revenue sharing contracts and service requirement under supply and demand uncertainty," International Journal of Production Economics, vol. 183, pp. 185-193, 2017.

[12] F. Lin, X. Qin, X. Pu, W. Zhu, and X. Zhuo, "Effects of inhouse production on channel structures in a co-opetitive supply chain under supply uncertainty," Omega, vol. 103, Article ID 102426, 2021. 
[13] K. Govindan, M. Fattahi, and E. Keyvanshokooh, "Supply chain network design under uncertainty: a comprehensive review and future research directions," European Journal of Operational Research, vol. 263, no. 1, pp. 108-141, 2017.

[14] M. W. Carter and C. C. Price, Operations Research: A Practical Introduction, CRC Press, Boca Raton, FL, USA, 2017.

[15] D. Huang, X. Chen, Z. Liu, C. Lyu, S. Wang, and X. Chen, "A static bike repositioning model in a hub-and-spoke network framework," Transportation Research Part E: Logistics and Transportation Review, vol. 141, Article ID 102031, 2020.

[16] D. Huang, J. Xing, Z. Liu, and Q. An, "A multi-stage stochastic optimization approach to the stop-skipping and bus lane reservation schemes," Transportmetrica A: Transport Science, vol. 17, no. 4, pp. 1272-1304, 2021.

[17] D. Huang, Y. Gu, S. Wang, Z. Liu, and W. Zhang, "A twophase optimization model for the demand-responsive customized bus network design," Transportation Research Part C: Emerging Technologies, vol. 111, pp. 1-21, 2020.

[18] H. H. Turan, M. N. Serarslan, and N. Kasap, "A fuzzy stochastic model for telecommunications bandwidth brokers under probabilistic QoS measures," Applied Mathematical Modelling, vol. 38, no. 1, pp. 12-27, 2014.

[19] B. Stefansdottir and M. Grunow, "Selecting new product designs and processing technologies under uncertainty: twostage stochastic model and application to a food supply chain," International Journal of Production Economics, vol. 201, pp. 89-101, 2018.

[20] G. Dantzig, A. Orden, and P. Wolfe, "The generalized simplex method for minimizing a linear form under linear inequality restraints," Pacific Journal of Mathematics, vol. 5, no. 2, pp. 183-195, 1955.

[21] A. Gupta and C. D. Maranas, "Managing demand uncertainty in supply chain planning," Computers \& Chemical Engineering, vol. 27, no. 8-9, pp. 1219-1227, 2003.

[22] Y. An, B. Zeng, Y. Zhang, and L. Zhao, "Reliable p-median facility location problem: two-stage robust models and algorithms," Transportation Research Part B: Methodological, vol. 64, pp. 54-72, 2014.

[23] A. Ghodratnama, R. Tavakkoli-Moghaddam, and A. Azaron, "Robust and fuzzy goal programming optimization approaches for a novel multi-objective hub location-allocation problem: a supply chain overview," Applied Soft Computing, vol. 37, pp. 255-276, 2015.

[24] F. Zhou, Y. Xu, C. Tang et al., "Review on the development of food waste management policy in China," Low-Carbon Economy, vol. 9, no. 2, p. 10, 2020.

[25] N. Geng and Y. Sun, "Multiobjective optimization of sustainable WCO for biodiesel supply chain network design," Discrete Dynamics in Nature and Society, vol. 2021, Article ID 6640358, 16 pages, 202.

[26] M. Eskandarpour, P. Dejax, J. Miemczyk, and O. Péton, "Sustainable supply chain network design: an optimizationoriented review," Omega, vol. 54, pp. 11-32, 2015.

[27] Z. Liu, T. Qiu, and B. Chen, "A study of the LCA based biofuel supply chain multi-objective optimization model with multiconversion paths in China," Applied Energy, vol. 126, pp. 221-234, 2014.

[28] Y. Ge, L. Li, and L. Yun, "Modeling and economic optimization of cellulosic biofuel supply chain considering multiple conversion pathways," Applied Energy, vol. 281, Article ID 116059, 2021.

[29] S. Giarola, A. Zamboni, and F. Bezzo, "Spatially explicit multiobjective optimisation for design and planning of hybrid first and second generation biorefineries," Computers \& Chemical Engineering, vol. 35, no. 9, pp. 1782-1797, 2011.

[30] Y. Wang and H. Li, "Research on prediction model of civil aviation accident symptomatic based on grey neural network," China Safety Science Journal, vol. 22, no. 3, pp. 10-15, 2012.

[31] E. Gao, T. Sowlati, and S. Akhtari, "Profit allocation in collaborative bioenergy and biofuel supply chains," Energy, vol. 188, Article ID 116013, 2019.

[32] G. Gosalbe, B. L. Montastruc, S. Negny et al., "Optimal design and planning of biomass-to-biofuel supply chain considering economic dimension under strategic and tactical levels: a case study in Ethiopia," Computer Aided Chemical Engineering, vol. 48, pp. 1111-1116, 2020.

[33] G. Baudry, "How the cap limit for food-crop-based biofuels may affect France's stakeholders by 2030? a range-based multi-actor multi-criteria analysis," Transportation Research Part D: Transport and Environment, vol. 63, pp. 291-308, 2018.

[34] X. Qin, N. Li, G. X. Li et al., "Current status and progress of food waste recycling technology," Coal \& Chemical Industry, vol. 38, no. 7, pp. 35-40, 2015.

[35] H. Uster and G. Memişoğlu, "Biomass logistics network design under price-based supply and yield uncertainty," Transportation Science, vol. 52, no. 2, pp. 474-492, 2017.

[36] G. Memisoglu, "Bio-energy logistics network design under price-based supply and yield uncertainty," Doctoral dissertation, Texas A \& M University, College Station, TX, USA, 2014.

[37] F. Xie, "Modeling sustainability in renewable energy supply chain systems," Dissertation, Clemson University, Clemson, SC, USA, 2015.

[38] Y. Zhang and Y. Jiang, "Robust optimization on sustainable biodiesel supply chain produced from waste cooking oil under price uncertainty," Waste Management, vol. 60, pp. 329-339, 2017.

[39] Y. Qi, Z. Wang, and Y. Li, "Cost analysis of food waste collection and transportation in Shanghai," Environmental Sanitation Engineering, vol. 16, no. 3, pp. 47-49, 2008.

[40] Y. Jiang, Robust Optimization of Sustainable Biofuel Supply Chain under Uncertain Conditions, Southeast University, Nanjing, China, 2016.

[41] P. Xu and X. Mu, "Application and development of kitchen waste in energy production," Modern Chemical Industry, vol. 36, no. 5, pp. 12-16, 2016.

[42] R. Chen, J. Jiang, R. Huang et al., "Overview of the recovery and reuse of gutter oil," Science and Technology Innovation and Application, vol. 211, no. 9, pp. 7-9, 2017.

[43] H. Chen, J. Liu, H. Zhong et al., "Carbon emission reduction potential analysis of different treatment modes of kitchen waste," Chinese Environmental Science, vol. 33, no. 11, pp. 2102-2106, 2013.

[44] T. R. P. Ramos, M. I. Gomes, and A. P. Barbosa-Póvoa, "Planning waste cooking oil collection systems," Waste Management, vol. 33, no. 8, pp. 1691-1703, 2013. 